Aragoneses de la Rubia, E. (2020). Caracterización de la isla de calor urbana en el campus de la UAM por medio de teledetección. GeoFocus, Revista Internacional de Ciencia y Tecnología de la Información Geográfica, 26, 43-67. http://dx.doi.org/10.21138/GF.678

\title{
CARACTERIZACIÓN DE LA ISLA DE CALOR URBANA EN EL CAMPUS DE LA UAM POR MEDIO DE TELEDETECCIÓN
}

\author{
ELENA ARAGONESES DE LA RUBIA (iD \\ Universidad Autónoma de Madrid \\ Campus Cantoblanco. Ctra. Colmenar, Km.15. 28049 Madrid \\ elena14ara@gmail.com
}

RESUMEN

La teledetección es una técnica que se puede emplear para el estudio térmico de las cubiertas del territorio y la caracterización de espacios según su capacidad de resistencia al sobrecalentamiento. El objetivo de este trabajo es caracterizar la isla de calor urbana (UHI) del campus de la Universidad Autónoma de Madrid (UAM) y determinar su grado de influencia por la UHI madrileña. Se trabaja con imágenes de los satélites Sentinel-2, Landsat 8 e imágenes de la campaña DESIREX, iniciativa de la ESA (Agencia Espacial Europea). Se calculan el índice de vegetación de diferencia normalizada (NDVI) y la temperatura de la superficie terrestre (LST), analizando para las cubiertas la evolución de temperaturas a lo largo del día, la amplitud térmica e identificando puntos calientes. Los resultados indican que el comportamiento térmico del campus se asemeja al de zonas rurales y no urbanas, y que no está influenciado significativamente por la UHI de la capital.

Palabras clave: teledetección; isla de calor urbana (UHI); temperatura de la superficie terrestre (LST); DESIREX; UAM; Madrid.

\section{CHARACTERIZATION OF THE URBAN HEAT ISLAND IN THE UAM CAMPUS USING REMOTE SENSING}

\section{ABSTRACT}

Remote sensing is a technique which can be used for the thermal study of the surface covers of the territory and the characterization of spaces based on their ability to withstand overheating. The objective of this work is to describe the urban heat island (UHI) of the Universidad Autónoma de Madrid (UAM) campus and to determine its degree of influence by Madrid's UHI. The work has been based on images from Sentinel-2 and Landsat 8 satellites, and images from the DESIREX campaign, an initiative of ESA (European Space Agency). Normalized difference vegetation index (NDVI) and land surface temperature (LST) of the surface covers are calculated and the evolution 
Aragoneses de la Rubia, E. (2020). Caracterización de la isla de calor urbana en el campus de la UAM por medio de teledetección. GeoFocus, Revista Internacional de Ciencia y Tecnología de la Información Geográfica, 26, 43-67. http://dx.doi.org/10.21138/GF.678

of temperatures throughout the day, the thermal amplitude and hot spots are analyzed. The results show that the thermal behavior of the campus is similar to that of rural and non-urban areas, and that it is not specially influenced by the capital's UHI.

Keywords: remote sensing; urban heat island (UHI); Land Surface Temperature (LST); DESIREX; UAM; Madrid.

\section{Introducción y antecedentes}

La teledetección consiste en la adquisición remota de información de la superficie terrestre mediante instrumentos y sensores que no están en contacto con la misma (Martínez Vega et al. 2010). Las imágenes se procesan a partir de la discriminación de energía proveniente de las diversas cubiertas a distintas longitudes de onda, variando según las características estructurales internas de cada material. Este trabajo se centra en la teledetección térmica, cuyo fundamento físico es la emisión de radiación térmica de objetos y superficies en función de su temperatura (Sykas, 2018a y 2018b). Con esta técnica se analizan las características, dimensiones y efectos de la isla de calor urbana del campus de la Universidad Autónoma de Madrid (UAM), comparándola con la de la urbe madrileña.

La isla de calor urbana (Urban Heat Island: UHI) consiste en la acumulación de calor en áreas urbanas con respecto a áreas no urbanizadas o cuya urbanización es menos intensa (Sobrino et al. 2013). Se define como: $\mathrm{UHI}=\mathrm{AT}_{\text {urbana }}-\mathrm{AT}_{\text {rural }}$ (Morris et al., 2001), siendo AT las siglas en inglés de 'temperatura atmosférica' (Atmospheric Temperature). La UHI es una temática importante de estudios actuales, pues sus efectos se agudizan con el cambio climático. El problema de la UHI como consecuencia de la urbanización fue documentado por primera vez por Howard en 1818 (Oke, 1982). Son muchas las técnicas que se pueden emplear para estudiar este fenómeno, incluida la teledetección (Mirzaei y Haghighat, 2010), usada por primera vez por Roa en 1972 para estudiar la UHI (Roa, 1972). En la actualidad son numerosos los estudios que abordan esta problemática desde esta perspectiva (Voogt y Oke, 2003; Rasul et al. 2017).

Existen dos tipos de UHI: la UHI atmosférica (UHIa), referida a la temperatura del aire y la UHI de calor superficial (UHIs), referida a la temperatura de las superficies. Los mecanismos de formación de ambas son distintos, así como las técnicas de identificación y medidas de mitigación. Este trabajo estudia el calor superficial urbano (UHIs) que afecta a la sensación térmica en el interior de los edificios. La UHIs se manifiesta durante el día y la noche, con máxima intensidad durante el verano. De entre otras metodologías, se puede estudiar con teledetección obteniendo imágenes térmicas. El principal método de mitigación de la UHI es la modificación de los tipos de materiales (EPA, 2003; Fernández García et al. 2016).

Para referirse a la UHIs cuando se estudia por medio de la teledetección, se puede emplear el término SUHI (Surface Urban Heat Island o Isla de Calor Urbana Superficial), referido a la temperatura de la superficie y no a la temperatura atmosférica (Sobrino et al. 2013). Esta denominación se justifica porque el estudio de la UHI con teledetección todavía se encuentra en estado de investigación y presenta limitaciones, aunque ya se han realizado importantes avances. Existen todavía diferencias de hasta $3{ }^{\circ} \mathrm{C}$ en zonas rurales y $15^{\circ} \mathrm{C}$ en zonas urbanas entre las temperaturas medidas del aire, medibles en los transectos en coche con instrumentación de campo, 
Aragoneses de la Rubia, E. (2020). Caracterización de la isla de calor urbana en el campus de la UAM por medio de teledetección. GeoFocus, Revista Internacional de Ciencia y Tecnología de la Información Geográfica, 26, 43-67. http://dx.doi.org/10.21138/GF.678

y las temperaturas de las cubiertas superficiales, medibles con teledetección (Sobrino et al. 2009a). Sin embargo, la teledetección tiene mucho potencial para estudiar la UHI, pues la temperatura urbana es difícil de medir con estaciones meteorológicas convencionales, normalmente localizadas en aeropuertos o parques (como en Madrid), por lo que los datos recogidos no son representativos de las condiciones reales de temperatura que sufre la población (Laaidi, 2012).

Estudiar la UHI es muy importante dado que actualmente un $54 \%$ (4,2 mil millones de personas) de los 7,7 mil millones de personas del mundo viven en áreas urbanas (cifras en 2019). De este porcentaje, un $79 \%$ corresponde a países desarrollados. Para 2030 se prevé alcanzar los 8,5 mil millones de personas en el mundo, de las que 5 mil millones vivirán en áreas urbanas, aproximadamente el $60 \%$ de la población mundial. Para 2050 se prevé el aumento de la población mundial en 9,8 mil millones de personas, viviendo el $68 \%$ en áreas urbanas (Population Reference Bureau, 2019; United Nations, 2019a y 2019b). Además, el estrés térmico de las ciudades está gravemente influenciado por la UHI, afectando a la salud y bienestar humano (Fernández García y Rasilla Álvarez, 2008). Para el campus de la UAM, la caracterización de la UHI y sus diferencias térmicas suponen el conocimiento teórico necesario para establecer medidas que la reduzcan y favorezcan el aumento de la calidad de vida de estudiantes, profesores y trabajadores.

\subsection{Caracterización de las UHIs}

Mayores dimensiones del espacio urbano ocupado suelen corresponderse con mayores dimensiones del efecto de la UHI (Mirzaei y Haghighat, 2010) y, en consecuencia, con mayor disminución de la calidad de vida de sus habitantes e incomodidad en el interior de los edificios (Voogt, 2002; Huang et al. 2005). Este fenómeno afecta negativamente al consumo energético de los edificios y la ciudad (Voogt y Oke, 2003; Hartz et al. 2005; Núñez Peiró et al. 2017), y a la calidad del aire (Sarrat, 2006), alterando la climatología local (patrones de vientos, formación de nubes y niebla, aumento de la humedad y alteración de precipitaciones) (Taha, 1997). Además, la UHI favorece las olas de calor extremas, pudiendo provocar muertes entre los colectivos más vulnerables, como los mayores de 70 años, tal y como ocurrió en París en 2003 (Laaidi et al. 2012). Sin embargo, debe considerarse que la intensidad de la UHI varía en función de la morfología de la ciudad, la ubicación y su zona climática (Pérez González et al. 2003; Hart y Sailor, 2009).

El efecto de la UHI aumenta en la mitad cálida del año y su intensidad es mayor durante la noche (Voogt y Oke, 2003; Pérez González et al. 2003). La principal causa de formación de la UHI son las características de acumulación del calor de los materiales de construcción, mayores que las de los elementos naturales (Mirzaei y Haghighat, 2010). Por ello, la ciudad se calienta más que las zonas no urbanizadas. Además, el efecto de la UHI se aprecia más durante la noche, cuando las ciudades se mantienen calientes porque emiten radiación de onda larga sin producirse demasiado enfriamiento (Fernández García et al. 2016). Es importante conocer la dinámica de formación de la UHI para elaborar estrategias de mitigación efectivas (Mirzaei y Haghighat, 2010). Según Bonan (2000), Oke (1973) y Svensson (2004), incluso asentamientos urbanos pequeños pueden sufrir los efectos de la UHI, existiendo tremendas variaciones de los microclimas en distancias pequeñas en estos espacios (Hartz et al. 2005; Fernández García y Rasilla Álvarez, 2008). Por ello, es interesante el estudio térmico y de la UHI del pequeño asentamiento del campus de la UAM. 
Aragoneses de la Rubia, E. (2020). Caracterización de la isla de calor urbana en el campus de la UAM por medio de teledetección. GeoFocus, Revista Internacional de Ciencia y Tecnología de la Información Geográfica, 26, 43-67. http://dx.doi.org/10.21138/GF.678

La temperatura ambiental de la UHI varía, no solo respecto a las zonas rurales colindantes, sino en función de las diferencias intraurbanas de usos del suelo y características de las cubiertas, que modifican el balance energético del espacio urbano (Hart y Sailor, 2009; Fernández García et al. 2016). Algunas de las características de las cubiertas que más afectan a la UHI son la densidad de edificios, la altura y sombras de las construcciones, las carreteras y la densidad del tráfico, los materiales empleados en la construcción y los espacios verdes (Bottyán y Unger, 2003; Stone y Norman, 2006; Unger, 2006), que reducen la evaporación, disminuyen la velocidad del viento e incrementan su turbulencia, y aumentan la escorrentía superficial (Fernández García et al. 2016). La actividad humana también afecta al microclima urbano (Sailor y Lu, 2004), influenciando el albedo de las superficies y la cantidad de energía acumulada por ellas. Así, muchos estudios (Toy et al. 2005; Hart y Sailor, 2009) remarcan la importancia de los espacios abiertos y forestales en las ciudades para suavizar el clima. Toy et al. (2005) proponen incrementar el área forestal en las ciudades como medida reguladora del clima, destacando la correcta selección de la especie arbórea. Las especies mediterráneas adaptadas a falta de agua estival no amortiguan la UHI, pues minimizan sus funciones vitales de absorción y cesión de humedad (Pérez y García, 2001).

\subsection{La UHI en Madrid / campus de la UAM}

Se presupone que la UHI en el campus de la UAM está gravemente influenciada por la UHI de Madrid. Publicándose en 1988 el primer estudio de la UHI madrileña, han sido numerosos y detallados los posteriores trabajos sobre su caracterización (como ejemplo, López Gómez et al. 1991). Algunos emplean la técnica de la teledetección (López Gómez et al. 1993; Pérez González et al. 2003; Núñez Peiró et al. 2017) y todos coinciden en la alta intensidad de la SUHI en la capital, aun teniendo variaciones espaciotemporales, así como en la dificultad del estudio de un fenómeno tan complejo. La UHI madrileña presenta mayor intensidad en verano, relacionándose directamente con el momento de mayor intensidad de la radiación solar incidente: el solsticio de verano en el hemisferio norte, la noche del 20 al 21 de junio, por estar el Sol más perpendicular en el hemisferio norte (mayor exposición temporal). El ciclo diario se mantiene constante durante el año: la UHI se empieza a formar a partir de las 22 horas, alcanza su máxima intensidad a las 5 horas y desaparece a las 7 horas (Fernández García et al. 2016; Núñez Peiró et al. 2017). Desde la perspectiva bioclimática, el estrés térmico dura las 24 horas del día, aumentando la sensación de malestar y los efectos negativos sobre la población (Fernández García y Rasilla Álvarez, 2012).

La ciudad de Madrid presenta una anomalía térmica: durante el día se calienta, pero presenta menor temperatura que su entorno no urbanizado (la ciudad actúa como isla de frío), y durante la noche libera el calor acumulado durante el día mientras que su entorno no urbanizado se ha enfriado rápidamente (la ciudad actúa como isla de calor) (López Gómez et al. 1993; Pérez González et al. 2003; Fernández García y Rasilla Álvarez, 2008). Por tanto, sería más correcto hablar de la UHI nocturna madrileña. Esta dinámica se refuerza por su entorno árido (cultivos de secano y bosque mediterráneo) y en episodios de calor intenso, como la ola de calor de 2003 (Fernández García y Rasilla Álvarez, 2008; Fernández García et al. 2016). Las diferencias térmicas en los momentos más cálidos del verano madrileño entre la ciudad y su entorno pueden alcanzar hasta $8^{\circ} \mathrm{C}$ (Núñez Peiró et al. 2016). Además, para Madrid, Núñez Peiró et al. (2017) determinan que pueblos y ciudades próximos presentan micro-UHIs de entre 1 y $3{ }^{\circ} \mathrm{C}$. El crecimiento urbano de la capital y la densidad de edificaciones ha propiciado la ampliación del área de afección de la 
Aragoneses de la Rubia, E. (2020). Caracterización de la isla de calor urbana en el campus de la UAM por medio de teledetección. GeoFocus, Revista Internacional de Ciencia y Tecnología de la Información Geográfica, 26, 43-67. http://dx.doi.org/10.21138/GF.678

UHI madrileña hacia otras zonas, así como aumentado su intensidad en hasta $+4{ }^{\circ} \mathrm{C}$ en los puntos que eran más calientes y que han sufrido escasos cambios del entramado urbanístico. Se aprecia la labor termorreguladora de espacios verdes como El Retiro (Fernández García et al. 2003; Pérez González et al. 2003; Fernández García et al. 2016).

\subsection{Objetivos e hipótesis}

Este trabajo se encuadra en el estudio de la climatología urbana porque investiga la SUHI superficial del campus de la UAM y su relación con la SUHI de Madrid por medio de la teledetección, centrándose en la relación de la temperatura superficial con los usos de suelo y las cubiertas que configuran el espacio. El objetivo de este trabajo es describir la isla de calor urbana (UHI) del campus de la UAM y determinar su grado de influencia por la UHI madrileña. Se analizan imágenes de los satélites Sentinel-2 y Landsat 8, y los datos de la campaña DESIREX, iniciativa de la ESA. Se calculan el NDVI, LST y estadísticos. Se parte de la hipótesis de que la gran cantidad de superficie ocupada por espacios verdes en el campus favorece las corrientes de aire que regulan la temperatura del área. Además, se parte de la idea de que los usos del suelo y las construcciones determinan significativamente los focos calientes. La LST y la intensidad de la SUHI se consideran buenos indicadores del malestar de la población que habita una determinada área. Sin embargo, se señala que se trata de una aproximación a un problema de cierta complejidad.

\section{Materiales, datos y métodos}

\subsection{El caso de estudio. Delimitación espacial}

El área de estudio es el campus de la Universidad Autónoma de Madrid (UAM), para lo cual primero se realiza una aproximación a la situación térmica de Madrid y su entorno (Figura 1).

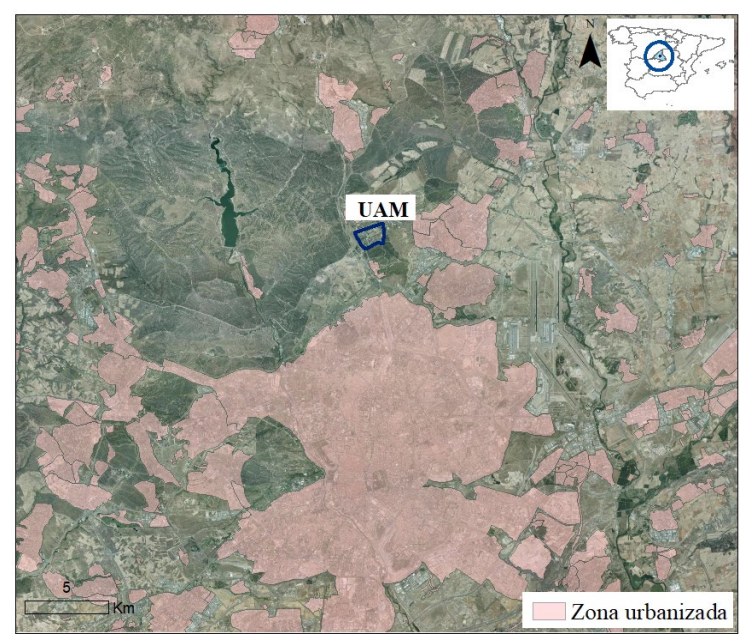

Figura 1. Área de estudio. A partir del MTN50 hojas 0534 y 0559 , y capas vectoriales del IGN. 
Aragoneses de la Rubia, E. (2020). Caracterización de la isla de calor urbana en el campus de la UAM por medio de teledetección. GeoFocus, Revista Internacional de Ciencia y Tecnología de la Información Geográfica, 26, 43-67. http://dx.doi.org/10.21138/GF.678

Madrid es la capital de España, con 3.266.126 habitantes empadronados en el municipio de Madrid y una densidad de población de 5265,91 hab/ $\mathrm{km}^{2}$ según el INE (Instituto Nacional de Estadística) en 2019. Su altitud media es de $657 \mathrm{~m}$ (IGN, hoja 559 MTN50). El clima es mediterráneo continental con gran amplitud térmica anual (veranos cálidos y secos e inviernos moderados). Es un área muy densamente urbanizada con diversos desniveles producto de la erosión diferencial del sustrato de arcosas por arroyos previos a su desarrollo (IGME, hoja 559 1:50 000).

El campus de la UAM se localiza en el municipio de Madrid, aproximadamente a $20 \mathrm{~km}$ de la capital. Su altitud media es de 750 m (IGN, hoja 534 MTN50), 93 m más que Madrid. El clima es el mismo que en la capital, con temperaturas ligeramente más suaves dada su mayor altitud, su proximidad a la Sierra de Guadarrama (mayor enfriamiento nocturno), y sus construcciones abiertas con espacios verdes y zonas deportivas (Figura 2). Se sitúa en una vaguada de arcosas muy erosionables. Destaca la cercanía al Monte de Valdelatas, dehesa de aproximadamente 300 ha al sur del campus (Génova Fuster, 1989). La construcción del campus (1968) data del periodo franquista en España. Por ello, su construcción responde a motivos estratégicos y la estructura de los edificios más antiguos no favorece los espacios de concentración de personas (Gómez Mendoza et al. 1987). Así, se favorecen los desequilibrios térmicos y la acumulación de calor en pisos altos. Sin embargo, esta no parece haber sido una preocupación prioritaria, pues los edificios antiguos carecen de dispositivos de evaluación del calor, ventanas preparadas para evitar la insolación o calefacción regulable. Este estudio puede servir para mejorar la calidad de vida de quienes "habitan" el campus.

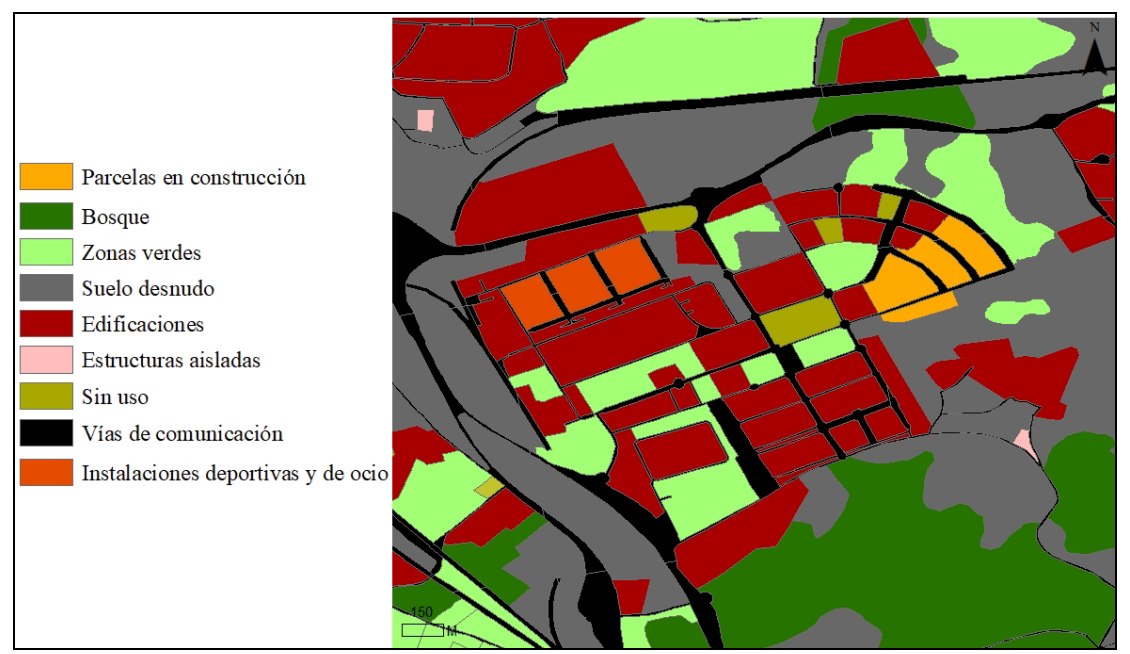

Figura 2. Usos de suelo del campus de la UAM. A partir de Urban Atlas, descargado del IGN.

\subsection{Materiales, datos y técnicas de análisis}

La metodología es cualitativa y cuantitativa, combinando la revisión bibliográfica con el análisis de imágenes con técnicas de teledetección. Para esto último se emplearon imágenes obtenidas con tres sensores: el MSI del satélite Sentinel-2 (ESA, 2020), los sensores OLI y TIRS del satélite Landsat 8 (Masek et al., 2019), y el sensor AHS empleado en la campaña DESIREX. Se trabaja con imágenes de reflectividad de Sentinel-2 y Landsat 8 ya corregidas atmosféricamente, 
Aragoneses de la Rubia, E. (2020). Caracterización de la isla de calor urbana en el campus de la UAM por medio de teledetección. GeoFocus, Revista Internacional de Ciencia y Tecnología de la Información Geográfica, 26, 43-67. http://dx.doi.org/10.21138/GF.678

mientras que las imágenes del AHS se obtienen a partir de los datos brutos de DESIREX, siendo necesario realizar el tratamiento y correcciones pertinentes, explicadas en esta sección.

\section{A) Imagen de Sentinel-2}

La imagen de Sentinel-2 empleada es del 26/06/2019 (diurna) y fue descargada del portal Copernicus Open Sci Hub, siendo esta fecha la imagen más actual de calidad para el día y mes lo más parecido a los de las imágenes de DESIREX de 2008. El satélite está operativo desde 2015, por lo que no fue posible trabajar con una imagen del mismo año que las de DESIREX (2008), pero es de utilidad para estudiar la situación actual y la hace comparable con la imagen de Landsat 8. Esta imagen no fue empleada para el estudio térmico, sino para el de vegetación.

Sentinel-2 es una misión de observación de la superficie terrestre desarrollada por la ESA (Agencia Espacial Europea) como parte del programa Copernicus. Está compuesto por un par de satélites, Sentinel-2A y Sentinel-2B, que adquieren imágenes multiespectrales en el visible, infrarrojo cercano e infrarrojo de onda corta. Tiene alta resolución, de 10 y $20 \mathrm{~m}$ para la mayoría de las bandas, y $60 \mathrm{~m}$ para las tres dedicadas a medir las perturbaciones atmosféricas (USGSc, 2019). Con el software SNAP (Sentinel Application Platform), se calculó para la imagen mediante Band Maths (Matemáticas de banda) el índice de NDVI (Índice de Vegetación de Diferencia Normalizada) que resalta la vegetación sana, cuya fórmula es NDVI = (IRcercano - Rojo) / (IRcercano + Rojo) donde 'IRcercano' corresponde a la Banda $8(842 \mathrm{~nm})$ de Sentinel-2 y 'Rojo' a la Banda $4(665 \mathrm{~nm})$. Los resultados se encuentran entre -1 y 1 , siendo 1 el valor máximo indicativo de presencia de vegetación sana. Además, se calcularon con SNAP las firmas espectrales de cuatro enclaves significativos de la imagen por sus diferencias en los valores de NDVI.

\section{B) Imagen de Landsat 8}

La imagen de Landsat 8 es del 02/07/2019, diurna. Landsat 8 es un satélite multiespectral propiedad de la NASA (National Aeronautics and Space Administration) operativo desde febrero de 2013 (Masek et al. 2019), por lo que no resultó posible el empleo de una imagen de este satélite para el mismo año (2008) que las imágenes de DESIREX. La fecha elegida se corresponde con la imagen sin nubosidad más actual y próxima a la fecha (día y mes) del solsticio de verano. La información térmica ofrecida resulta muy apropiada y de alta calidad para el estudio térmico.

La imagen de Landsat 8 del 02/07/2019 fue descargada en nivel L1TP (calibrado y ortorrectificado radiométrica y geométricamente) (USGSb) desde el portal Glovis (USGSa), siendo relevantes para el estudio térmico la Banda 10 (infrarrojo de onda larga: 10,60-11,19 $\mu \mathrm{m}$ ), la Banda 4 (rojo: 0,64-0,67 $\mu \mathrm{m}$ ) y la Banda 5 (infrarrojo cercano NIR: 0,85-0,88 $\mu \mathrm{m}$ ) (Avdan y Jovanovska, 2016). De estas bandas se deriva la información necesaria para calcular la LST, tarea realizada en base a las especificaciones de la guía de producto del código de tratamiento de las imágenes de Landsat 8 (Zanter, 2019), trabajando con los metadatos de la imagen y el algoritmo de temperatura LaSRC desarrollado previamente para esta cuestión (Avdan y Jovanovska, 2016; Anandababu et al. 2018). Los cálculos se hicieron utilizando el programa SNAP mediante la herramienta Band Maths. 
Aragoneses de la Rubia, E. (2020). Caracterización de la isla de calor urbana en el campus de la UAM por medio de teledetección. GeoFocus, Revista Internacional de Ciencia y Tecnología de la Información Geográfica, 26, 43-67. http://dx.doi.org/10.21138/GF.678

A partir de la Banda 10, se calcula la radiancia en la parte superior de la atmósfera (TOA: Top of Atmospheric Spectral Radiance) y con ella la temperatura de brillo (BT TOA: Brightness temperature); y a partir de las Bandas 4 y 5 se calcula el índice de vegetación NDVI, con lo que se calcula la proporción de la vegetación ( $\mathrm{P}_{\mathrm{v}}$ : Proporción de Vegetación) y la emisividad de la superficie terrestre (LSE: Land Surface Emissivity). Combinando las imágenes BT TOA y LSE se obtiene la imagen de temperatura de la superficie terrestre (LST) (Figura 3). La resolución de la Banda 10 de $100 \mathrm{~m}$ determina la resolución final de la imagen LST, imposibilitando caracterizar térmicamente las cubiertas de la pequeña área del campus de la UAM. Además, Landsat 8 no está diseñado para adquisición de imágenes nocturnas porque emplea la radiación solar como fuente de energía. Se necesita investigación adicional para obtener una serie continua de datos nocturnos de calidad del planeta (Levin y Phinn, 2006). Por ello, esta imagen se usó para la observación de algunos aspectos clave del funcionamiento de la SUHI diurna de Madrid.

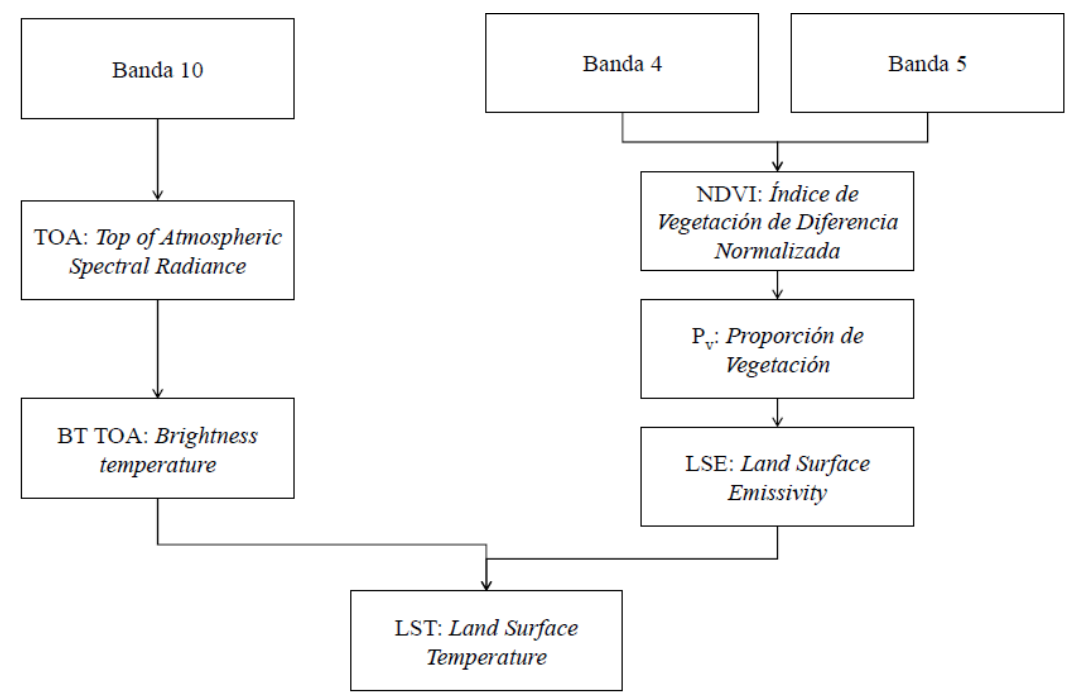

Figura 3. Aplicación del algoritmo de temperatura LaSRC. A partir de Avdan y Jovanovska, 2016 y Zanter, 2019.

C) Imágenes de la campaña DESIREX 2008 en Madrid

Para el estudio de la SUHI en el campus de la UAM, se decidió trabajar con los datos de la campaña experimental DESIREX (Dual-use European Security IR Experiment), llevada a cabo en Madrid en 2008 (Figura 4). Esta campaña fue desarrollada como parte del marco de actuación de Earth Observation Programmes de la ESA (Agencia Espacial Europea) cuyo objetivo fue la obtención de material que fuera soporte para el desarrollo de sensores de infrarrojo, desarrollo de algoritmos, tareas de calibración y validación, proporcionar un estudio que favoreciera la adopción de políticas de eficiencia energética, y la simulación de estrategias de muestreo a emplear en futuras misiones de observación de la superficie terrestre, la atmósfera y los océanos. Además, también estudió las temperaturas y variabilidad espacial de la SUHI y la UHI haciendo uso de sensores aeroportados y realizando las mismas mediciones en transectos en coche. Esta campaña fue dirigida por la Unidad de Cambio Global de la Universidad de Valencia. Se eligió Madrid como objeto de 
Aragoneses de la Rubia, E. (2020). Caracterización de la isla de calor urbana en el campus de la UAM por medio de teledetección. GeoFocus, Revista Internacional de Ciencia y Tecnología de la Información Geográfica, 26, 43-67. http://dx.doi.org/10.21138/GF.678

estudio ya que es una de las ciudades europeas que sufre más olas de calor, llegando a alcanzar los $50{ }^{\circ} \mathrm{C}$ (Sobrino et al. 2009a, 2009b y 2013). Esta campaña fue realizada como preparación para el lanzamiento del proyecto Urban Heat Islands and Urban Thermography de la ESA, iniciado en septiembre de 2008, cuyo objetivo era dotar a Europa de las tan necesarias competencias a medio y largo plazo en imágenes de infrarrojo térmico de alta resolución (Data user element, 2008).

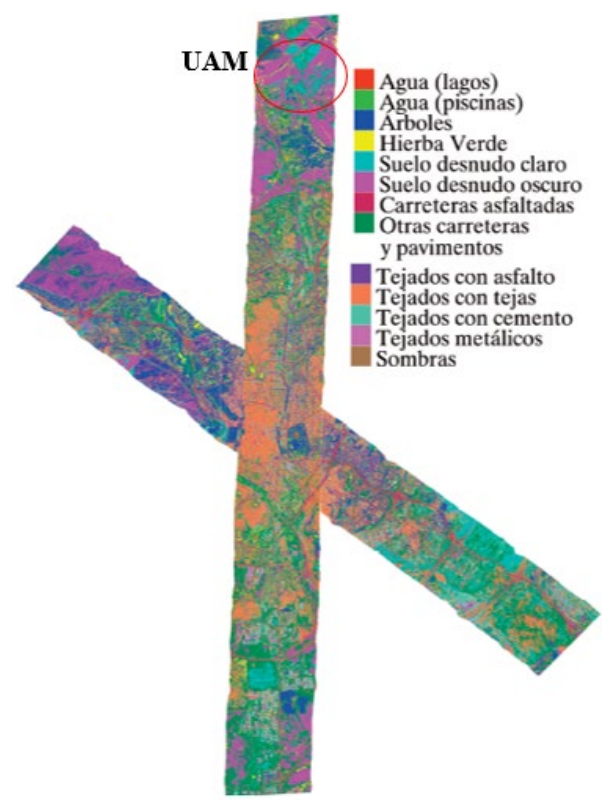

Figura 4. Mapa de clasificación de los dos transectos de la campaña DESIREX sobre Madrid y localización del campus de la UAM. Las coordenadas geográficas centrales con Datum WGS84 del recorrido del primer transecto son noroeste-sureste $N 4^{\circ} 28^{\prime} 48,8^{\prime \prime}$ / $\mathrm{W}^{\circ} 48^{\prime} 15,2^{\prime \prime}$ - N 40 $20 ' 56,0^{\prime \prime}$ / W $3^{\circ} 33^{\prime} 53,5^{\prime}$ y las del segundo transecto son sur-norte

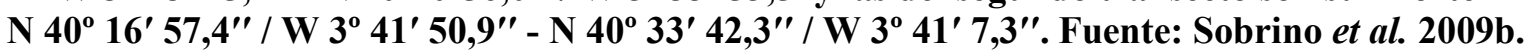

La principal instrumentación empleada en la campaña DESIREX fue el AHS (Airborne Hyperspectral Scanner) (Sobrino et al. 2009a, 2009b y 2013), un sensor hiperespectral aeroportado en avión propiedad del INTA (Instituto Nacional de Técnica Aeroespacial), una institución puntera en investigación en teledetección. El AHS tiene 80 canales espectrales para longitudes de onda en el visible e infrarrojo de onda corta y térmico (Data user element, 2008). Durante la campaña se realizaron 15 vuelos, ejecutados el 25, 26 y 28 de junio; y el 1, 2 y 4 de julio, a diferentes horas del día. Las pasadas de los vuelos fueron realizadas a diferentes GIFOV (Ground Instantaneous Field of View) variando entre 2,5 y 6,8 m, siendo $4 \mathrm{~m}$ el GIFOV más frecuente. Las imágenes fueron adquiridas siguiendo dos transectos (Figura 4). Además de parte de Madrid, en la imagen del segundo transecto se observa el campus de la UAM. Las imágenes fueron tratadas posteriormente (correcciones atmosféricas, georreferenciación, tratamiento con algoritmos, corrección de píxeles anómalos, etcétera) por los equipos del INTA y la ESA (Sobrino et al. 2009a y 2009b; Sobrino et al. 2013). La ventaja de estos datos reside en que se dispone de imágenes nocturnas, menos frecuentes y difíciles de obtener con teledetección. Se señala que los materiales de algunas cubiertas han variado desde 2008, pero esto no resulta significativo. 
Aragoneses de la Rubia, E. (2020). Caracterización de la isla de calor urbana en el campus de la UAM por medio de teledetección. GeoFocus, Revista Internacional de Ciencia y Tecnología de la Información Geográfica, 26, 43-67. http://dx.doi.org/10.21138/GF.678

Los resultados de la campaña fueron mapas de temperatura y SUHI de Madrid. Se observó que el efecto de la SUHI era mayor durante la noche y antes del amanecer, alcanzándose valores en la ciudad de hasta $+6{ }^{\circ} \mathrm{C}$ respecto a sus alrededores. Se explica que la capacidad para almacenar calor de los edificios y el suelo es mayor que la de la vegetación, y por ello el área urbana emite más radiación infrarroja (calor) durante la noche. Asimismo, concluye que $100 \mathrm{~m}$ es un tamaño de píxel adecuado para una correcta apreciación de la SUHI de la ciudad, aunque a mayor resolución espacial, mayor calidad de los resultados (Sobrino et al. 2009a y 2009b; Sobrino et al. 2013). La ESA ofrece las imágenes de esta campaña para investigación a través de solicitud.

En el presente trabajo se analizan 6 imágenes de DESIREX por ser las únicas que ofrecen datos para periodos de prácticamente 24 horas. Las imágenes corresponden al segundo transecto y a dos días. Por cada día se analizó una imagen diurna, una nocturna y una de madrugada: 13:27h del 25/06/2008, 00:31 del 26/06/2008, 06:26 del 26/06/2008 y 13:44 del 01/07/2008, 00:12 del 02/07/2008, 06:26 del 02/07/2008 (horas en el sistema horario de Europa central, GMT+2 en verano). La temporalidad de las imágenes permitió el análisis de la evolución diaria de temperatura (LST) y comparación entre días. Las imágenes LST de la campaña fueron pedidas a la ESA. Sin embargo, finalmente se optó por la elaboración propia de estas imágenes, con la ventaja de un mayor control de los parámetros determinantes de su calidad. Para ello se recurrió al Área de Teledetección del INTA, equipo con conocimiento técnico suficiente de la campaña y que posee la tecnología capaz de tratar las imágenes. Con su colaboración, se obtuvieron las imágenes LST a partir de los datos brutos de la campaña, de los que disponía el INTA por participar en ella en 2008.

Tras varias sesiones de trabajo en las instalaciones del INTA, se realizó la corrección atmosférica empleando las mediciones de las variables climáticas del día y hora de adquisición de cada imagen recogidas en Sobrino (2009a); y la transformación a LST con el software ATCOR4 siguiendo el algoritmo de temperatura TES (de separación de temperatura / emisividad) para las 5 bandas del térmico del sensor del satélite ASTER, que transforma radiancia en el sensor a LST (Gillespie et al. 1998; Gillespie et al. 1999); previa adaptación a las 9 bandas del térmico del sensor AHS (entre 8 y $13 \mu \mathrm{m}$ ) empleado en DESIREX (Carretero y De Miguel, 2015). Se eligió este algoritmo porque fue el escogido por el equipo que en 2008 realizó las transformaciones de las imágenes a LST (Sobrino, 2009a). TES se basa en que la superficie irradia energía en proporción a su temperatura. Es un algoritmo complejo que primero estima las emisividades normalizadas y después los ratios de emisividad para finalmente obtener la LST. Se señala la limitación de que ningún método de transformación a LST es óptimo para todas las cubiertas de la superficie. El error teórico de la aplicación del TES es de $\pm 1,5^{\circ} \mathrm{C}$. Sin embargo, la adaptación de estos algoritmos se ha estudiado principalmente para superficies naturales, por lo que, aplicados a algunas superficies artificiales, como las metálicas, puede derivar en datos anómalos (Carretero y De Miguel, 2015). Esto ocurrió en pequeñas superficies de las imágenes trabajadas, que fueron eliminadas del análisis.

Siguiendo el modo de trabajo del Área de Teledetección del INTA, obtenidas las imágenes LST se georreferenciaron sincronizando por tiempo los ficheros del GPS del sensor AHS y del avión, además de considerar los datos de posición y orientación del vuelo. Con estos datos y la información altitudinal de un MDE (Modelo Digital de Elevaciones) descargado del IGN, se calcularon con el software ENVI las coordenadas de cada píxel, se reconstruyeron las imágenes de salida empleando interpolación de píxeles sin dato por el método del vecino más próximo (para que todos los datos tuvieran una correspondencia real del registro del sensor y no falsear la realidad), y se fijó una resolución muy alta de $4 \mathrm{~m}$ el píxel de salida (la opción más pequeña que no derivaba en 
Aragoneses de la Rubia, E. (2020). Caracterización de la isla de calor urbana en el campus de la UAM por medio de teledetección. GeoFocus, Revista Internacional de Ciencia y Tecnología de la Información Geográfica, 26, 43-67. http://dx.doi.org/10.21138/GF.678

repetición de píxeles y valores). Además, se establecieron el Datum, la proyección y el sistema de coordenadas de las imágenes de salida en WGS84 y UTM 30N. Las imágenes resultantes están $2^{\circ}$ rotadas hacia el este respecto al norte geográfico (efecto de la proyección UTM). Se señala que la georreferenciación es una aproximación de la realidad al representarla en un plano bidimensional.

Realizadas estas tareas iniciales se procesaron y analizaron los datos en el software ArcGIS 10.4 de ESRI, donde se prepararon las imágenes LST analizadas, se elaboró cartografía de los puntos calientes y se calculó mediante la calculadora ráster la amplitud térmica diaria para ambos días restando la imagen LST de la madrugada (con los valores más bajos de LST) a la imagen del mediodía (con los valores más altos de LST). Se calcularon estadísticos básicos (media muestral y desviación estándar) para 4 cubiertas de diferente comportamiento térmico. El muestreo aleatorio estratificado recogió 5 polígonos para cada tipo de cubierta, considerando un total de 1718 píxeles para puntos calientes, 2867 para edificios, 1256 para pavimento y 4653 para zonas verdes. Se empleó la media dado que demostró ser un estimador robusto de la centralidad de los datos con valores muy similares a la mediana. Se prepararon tablas y gráficos de los resultados en Excel.

\section{Descripción y análisis de resultados}

La magnitud de la isla de calor urbana superficial (SUHI) está influenciada por los usos del suelo y su transformación en tejido urbano. Se procede a un acercamiento de este fenómeno en el área de estudio. Primero se realiza una aproximación de la SUHI madrileña mediante el análisis del NDVI a partir de la imagen de Sentinel-2 y la LST derivada de la imagen de Landsat 8 (Figura 5), para comparar posteriormente sus características con las del campus de la UAM.

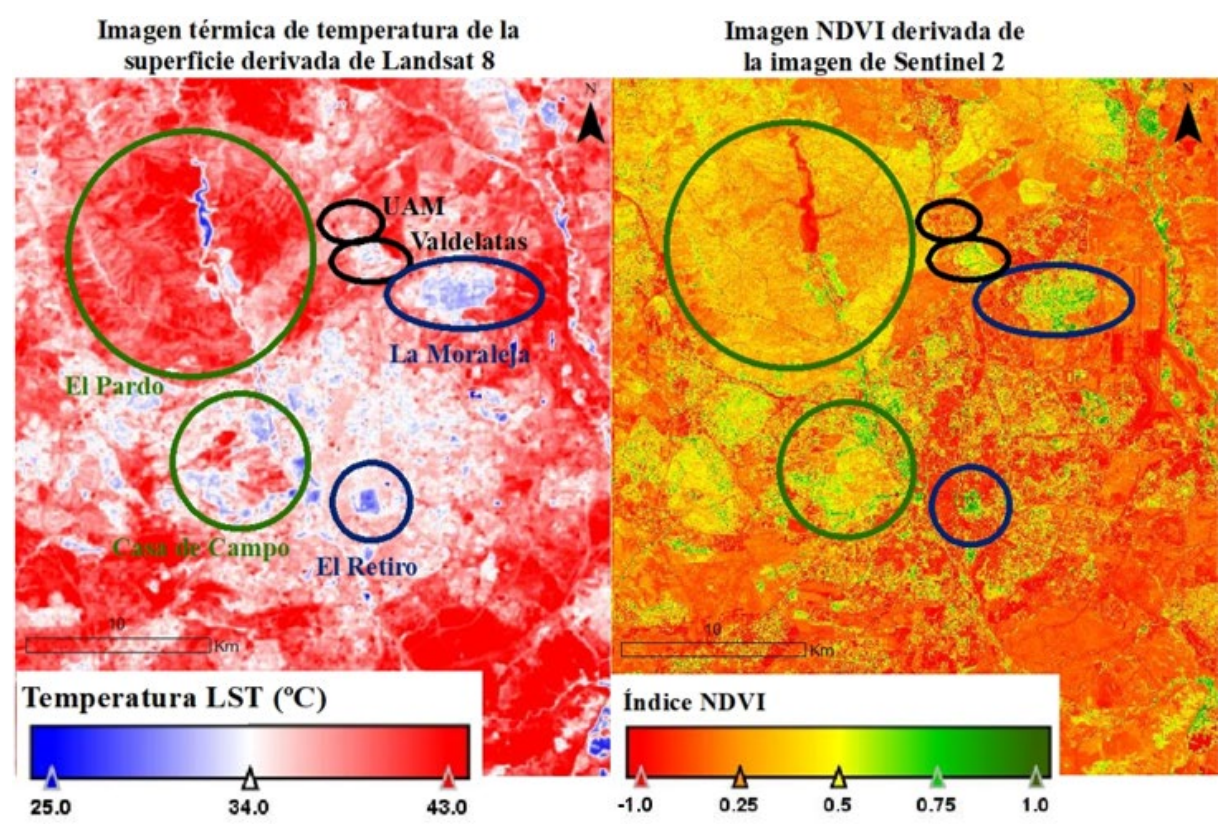

Figura 5. A la derecha, imagen NDVI a partir de imagen de Sentinel-2 (26/06/2019). A la izquierda, imagen LST $\left({ }^{\circ} \mathrm{C}\right)$ a partir de imagen de Landsat $8(02 / 07 / 2019)$. 
Aragoneses de la Rubia, E. (2020). Caracterización de la isla de calor urbana en el campus de la UAM por medio de teledetección. GeoFocus, Revista Internacional de Ciencia y Tecnología de la Información Geográfica, 26, 43-67. http://dx.doi.org/10.21138/GF.678

La resolución espacial de $100 \mathrm{~m}$ de la imagen de Landsat 8 permite visualizar Madrid en conjunto, sin atender al detalle de las cubiertas. El campus de la UAM se visualiza muy pequeño, observándose el efecto termorregulador de Valdelatas. Para la imagen de Landsat 8, la LST oscila entre $25-43^{\circ} \mathrm{C}$. Existe gran diferencia térmica según ocupación del suelo (hasta $18^{\circ} \mathrm{C}$ ). Se advierte la UHI diurna madrileña: temperaturas más altas en el exterior de la urbe y áreas poco urbanizadas.

Observando en detalle la imagen LST (Figura 5), se procede a la diferenciación térmica de espacios verdes. Por un lado, en la Figura 5 se visualizan espacios verdes con temperaturas más bajas respecto a las zonas colindantes. Destacan el parque de El Retiro, ya estudiado por numerosos autores (Fernández García et al. 2003; Pérez González et al. 2003; Fernández García et al. 2016) y la Moraleja, que, aunque se sitúa a las afueras de la urbe, resulta significativa su diferencia de temperatura respecto al resto de cubiertas. Ambas cubiertas presentan valores de LST cercanos a $25^{\circ} \mathrm{C}$. En contraposición, la Casa de Campo y El Pardo presentan valores de LST altos en comparación con los espacios urbanizados vecinos, y de NDVI bajos comparados con El Retiro y la Moraleja. La explicación reside en el índice NDVI y las firmas espectrales de estas cubiertas (Figura 6), referidas a la cantidad de energía reflejada para cada longitud de onda medida. Las firmas espectrales son únicas (Price, 1994) y permiten la clasificación a nivel de especies vegetales (Cochrane, 2000). La capacidad termorreguladora de una cubierta se considera de calidad si el índice NDVI $\geq 0,4$ (Green Urban Data, 2019).
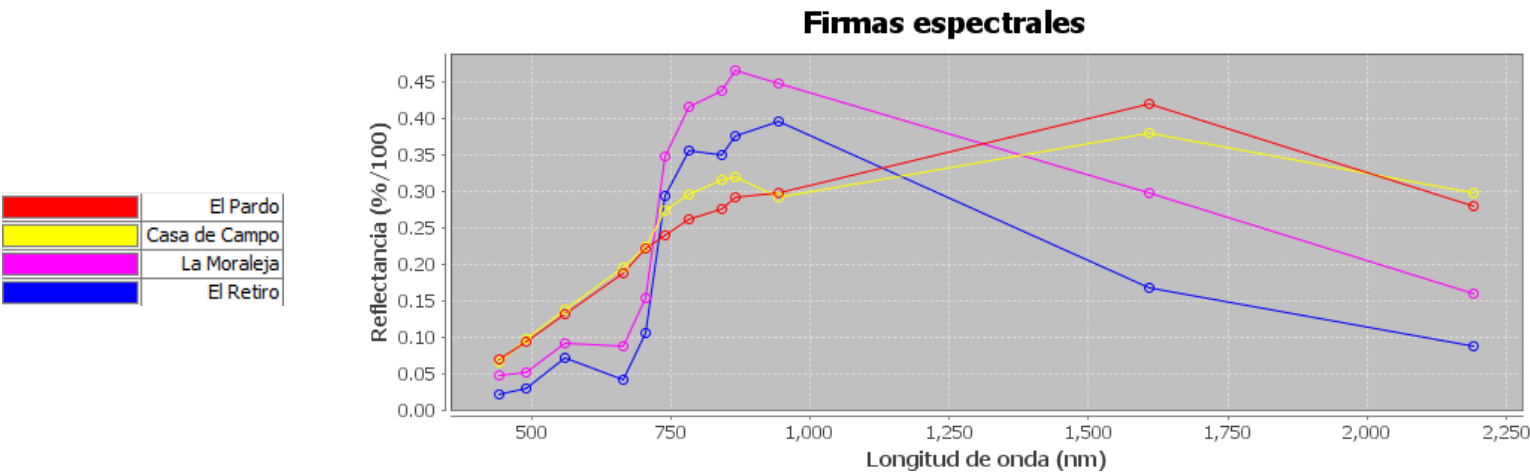

Figura 6. Firmas espectrales de las cubiertas de EI Pardo, la Casa de Campo, la Moraleja y EI Retiro calculadas en SNAP a partir de la imagen de Sentinel-2.

Las diferencias en el índice NDVI y las firmas espectrales se deben al tipo de hoja, función clorofílica, fenología, crecimiento y otras características ecológicas de la vegetación (Kachhwaha, 1983), haciendo referencia la absorción en el rojo $(645-700 \mathrm{~nm})$ al contenido de clorofila en las hojas (Tucker y Garratt, 1977) y la absorción en el infrarrojo (750 nm-1 mm) a la estructura celular (Danson, 1995). Las firmas espectrales (Figura 6) de El Retiro y la Moraleja se asemejan a las de la vegetación sana, con baja reflectancia en el rojo y alta en el infrarrojo cercano; mientras que las de El Pardo y la Casa de Campo se asemejan a las de suelo desnudo, incrementando progresivamente su reflectancia al aumentar la longitud de onda hasta el infrarrojo. Esto se debe a: 1) la menor densidad vegetal en estos últimos enclaves, espacios con significativa separación entre individuos, y 2) la menor evapotranspiración de la Casa de Campo y El Pardo, que a diferencia de El Retiro y la Moraleja no se riegan artificialmente. Por ello, la Casa de Campo y El Pardo se comportan, no como un espacio de vegetación termorregulador, sino como una superficie rural de baja 


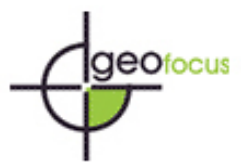

Aragoneses de la Rubia, E. (2020). Caracterización de la isla de calor urbana en el campus de la UAM por medio de teledetección. GeoFocus, Revista Internacional de Ciencia y Tecnología de la Información Geográfica, 26, 43-67. http://dx.doi.org/10.21138/GF.678

urbanización y suelo semidesnudo de alta LST, como las que rodean a la urbe. El campus de la UAM parece presentar un comportamiento similar al de la Casa de Campo y El Pardo.

Siguiendo con el estudio de la influencia en la temperatura de las cubiertas y usos del suelo, se procede al análisis del comportamiento térmico del campus de la UAM mediante las imágenes LST obtenidas a partir de los datos DESIREX. Poseen mayor resolución espacial que las de Landsat $8,4 \mathrm{~m}$ el píxel, posibilitando distinguir cubiertas dentro del campus (Figuras 7 y 8). Se analiza la evolución térmica diaria del 25-26/06/2008 y 01-02/07/2008 en el área de estudio a partir de tres imágenes cada día: mediodía, noche y madrugada. Los resultados para ambos días varían según las condiciones climáticas del día de adquisición de la imagen. Los píxeles anómalos con valores muy bajos de LST responden a la presencia de materiales metálicos y se han descartado del análisis.

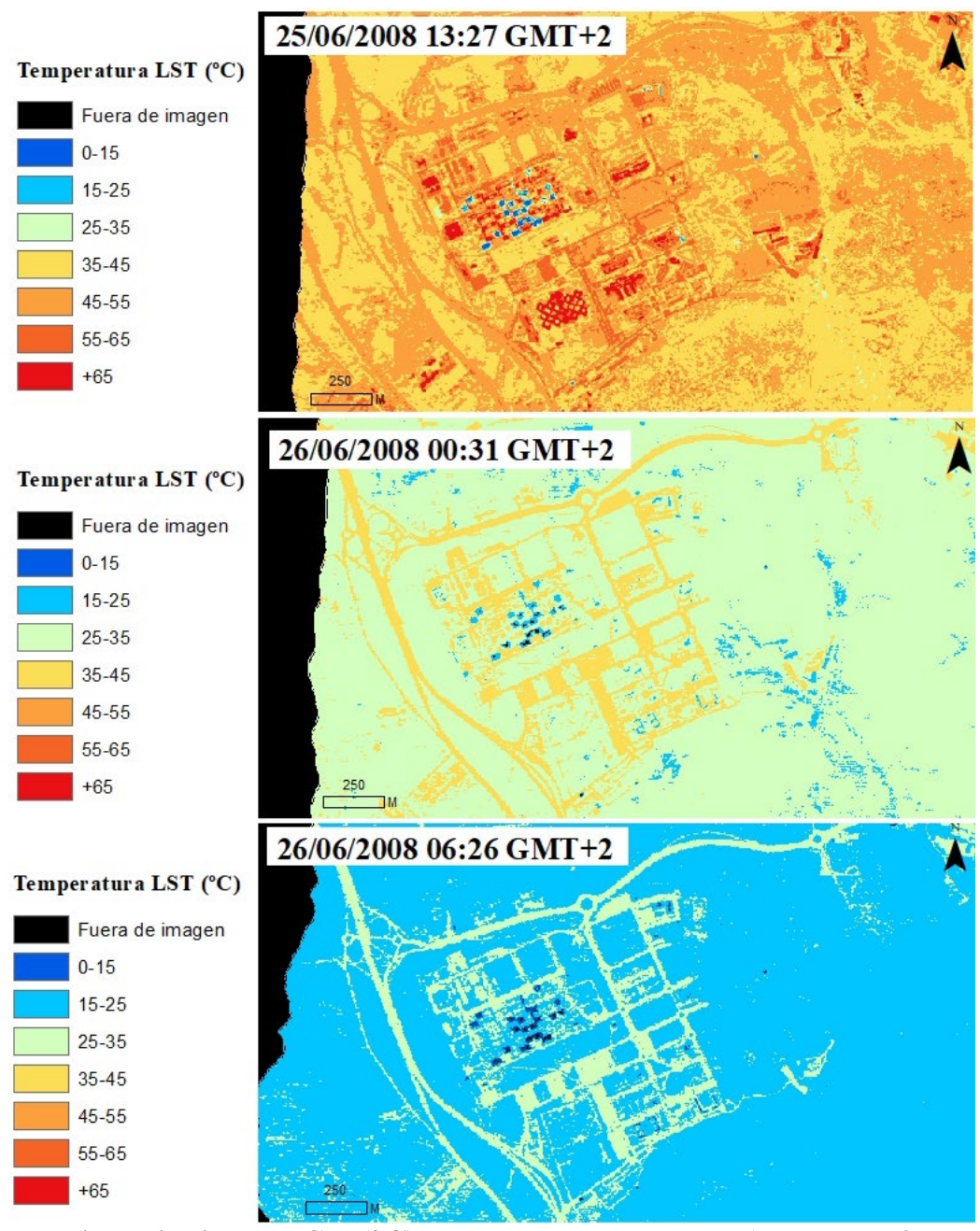

Figura 7. Evolución diaria de LST $\left({ }^{\circ} \mathrm{C}\right)$ en el campus de la UAM a partir de los datos de DESIREX para el 25-26/06/2008. 
Aragoneses de la Rubia, E. (2020). Caracterización de la isla de calor urbana en el campus de la UAM por medio de teledetección. GeoFocus, Revista Internacional de Ciencia y Tecnología de la Información Geográfica, 26, 43-67. http://dx.doi.org/10.21138/GF.678
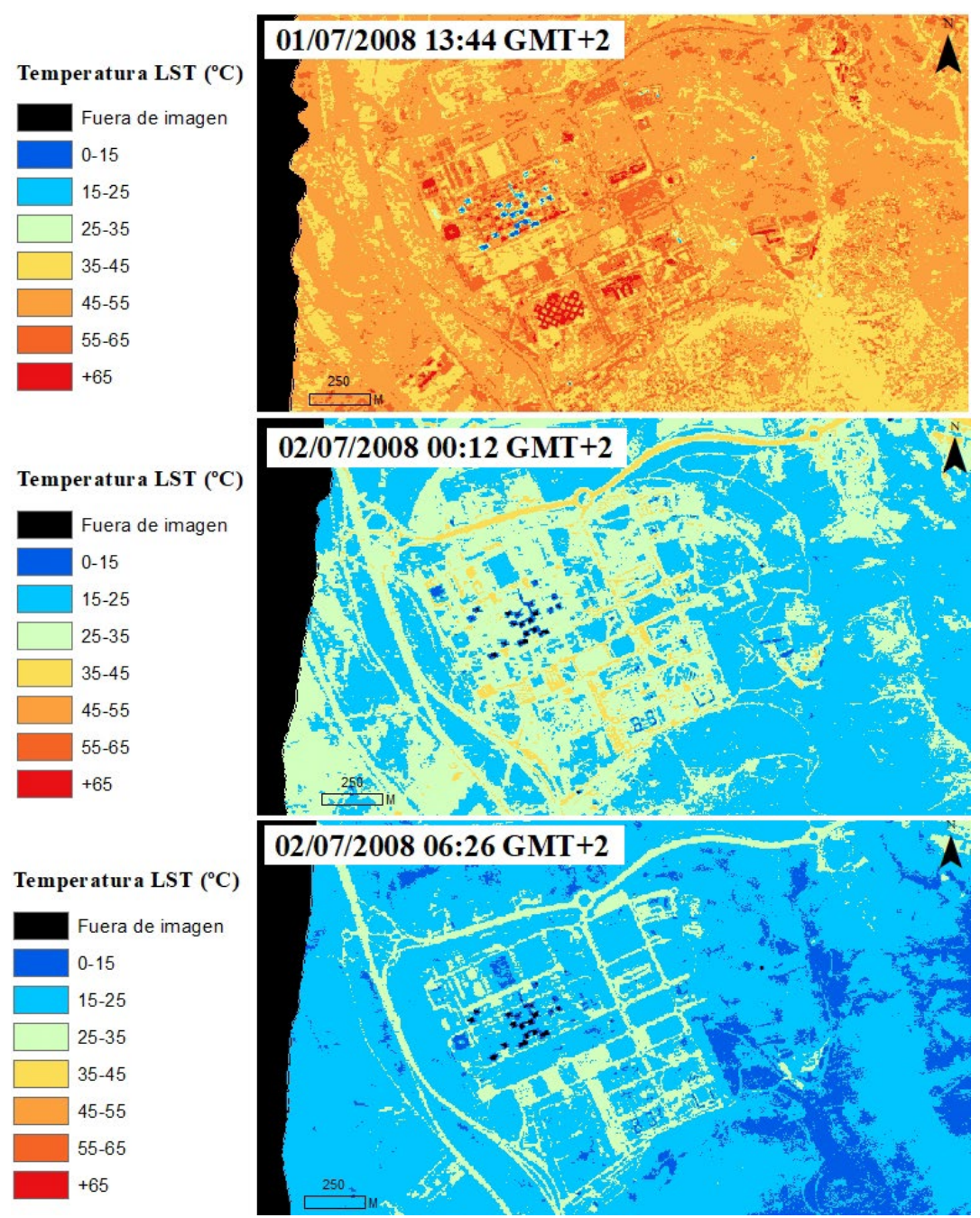

Figura 8. Evolución diaria de LST $\left({ }^{\circ} \mathrm{C}\right)$ en el campus de la UAM a partir de los datos de DESIREX para el 01-02/07/2008.

Los efectos de la SUHI en el campus de la UAM (Figuras 7 y 8) son menos acusados que para la urbe madrileña (Figura 5). El comportamiento de los dos días analizados es similar. Ambos presentan los valores más altos de LST al mediodía $\left(+35^{\circ} \mathrm{C}\right)$, intermedios al caer la noche (15$\left.45^{\circ} \mathrm{C}\right)$ y más bajos de madrugada $\left(0-35^{\circ} \mathrm{C}\right)$. En todas las imágenes a lo largo del día para ambos días se observan enclaves con temperaturas homogéneas. Los más calientes son algunos edificios (puntos calientes); con menor LST el pavimento, calles, carreteras y el resto de edificios; y siendo finalmente las zonas verdes o sin urbanizar aledañas las que presentan los valores mínimos de LST.

Se procede a analizar los puntos calientes o hot spots (Figura 9) del área de estudio, definidos como aquellos espacios y cubiertas que presentan las LSTs más altas, de más de $65^{\circ} \mathrm{C}$ a mediodía. Destacan como tal el polideportivo, una escuela infantil, la Escuela Politécnica superior, las facultades antiguas y el pabellón $\mathrm{B}$, la residencia de ancianos, la facultad de biología y el Club 
Aragoneses de la Rubia, E. (2020). Caracterización de la isla de calor urbana en el campus de la UAM por medio de teledetección. GeoFocus, Revista Internacional de Ciencia y Tecnología de la Información Geográfica, 26, 43-67. http://dx.doi.org/10.21138/GF.678

de tiro de la Federación madrileña. Las altas LST se dan al mediodía ambos días, coincidiendo con el momento en que estos edificios están habitados. En consecuencia, es esperable que las condiciones de habitabilidad en el interior de estos edificios sean de escasa calidad y exista incomodidad térmica y malestar de sus usuarios, dificultando las actividades a desempeñar y poniendo en riesgo a la población expuesta, sobre todo si se trata de población vulnerable como personas mayores (residencia de ancianos), niños (escuela infantil) o deportistas (polideportivo y Club de tiro) (Eurosocial, 2015; Sánchez González y Chávez Alvarado, 2016 y 2019). Los puntos calientes parecen estar relacionados con los usos del suelo y el material y estructura de los edificios construidos, características claves que diferencian los espacios y edificios térmicamente.
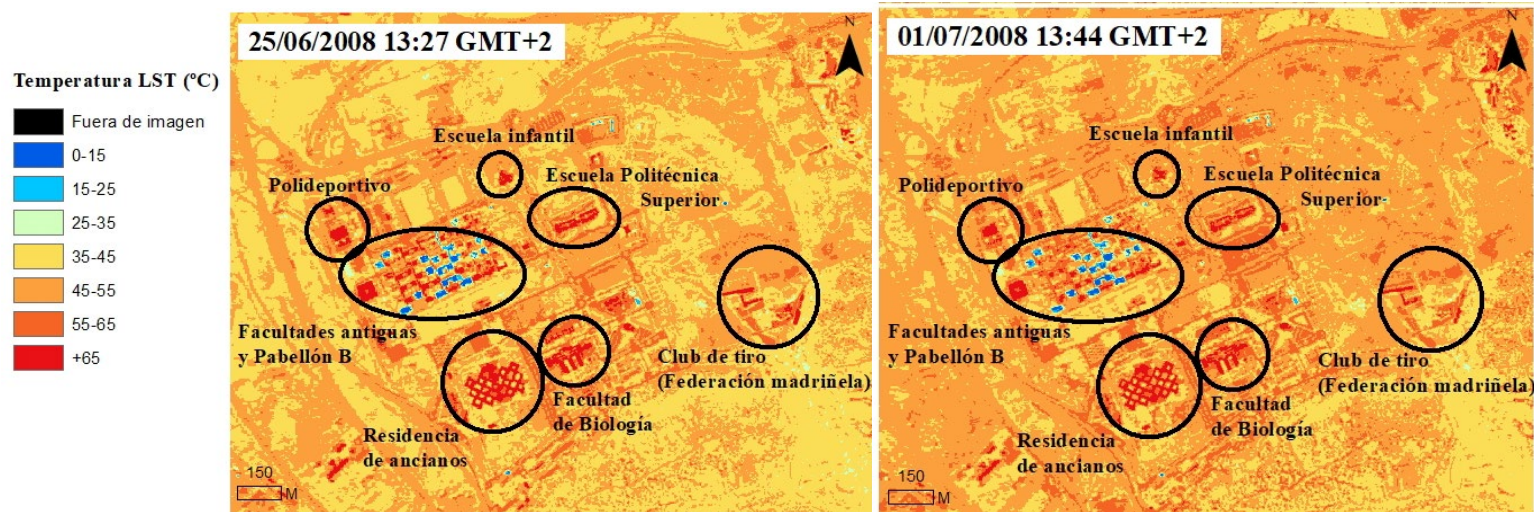

Figura 9. Puntos calientes (LST en ${ }^{\circ} \mathrm{C}$ ) del 25/07/2008 y 01/07/2008 a mediodía en el campus de la UAM. A partir de los datos de DESIREX.

A continuación, se analiza la amplitud térmica diaria (Figura 10) en el área de estudio.

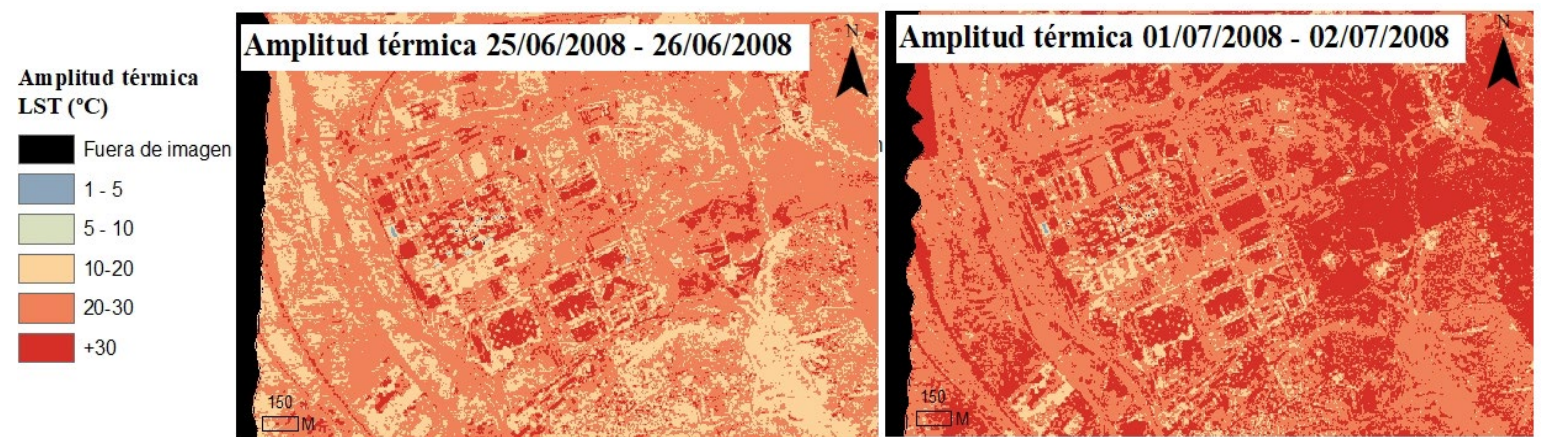

Figura 10. Imágenes de amplitud térmica diaria de LST $\left({ }^{\circ} \mathrm{C}\right)$ para el 25-26/06/2008 y 01 02/07/2008 en el campus de la UAM. A partir de los datos de DESIREX.

El día 01-02/07/2008 presenta mayor amplitud térmica diaria que el 25-26/06/2008, con los valores de LST más altos de las imágenes de mediodía y los más bajos de las de madrugada. Sin considerar los píxeles anómalos, la amplitud térmica para toda la imagen oscila entre $10-50{ }^{\circ} \mathrm{C}$. Especialmente para el 01-02/07/2008 abundan los píxeles con $+30{ }^{\circ} \mathrm{C}$ de amplitud térmica diaria. 
Aragoneses de la Rubia, E. (2020). Caracterización de la isla de calor urbana en el campus de la UAM por medio de teledetección. GeoFocus, Revista Internacional de Ciencia y Tecnología de la Información Geográfica, 26, 43-67. http://dx.doi.org/10.21138/GF.678

Por último, se analizan las características térmicas de cuatro cubiertas significativas por su diferente comportamiento: puntos calientes, edificios no considerados puntos calientes, pavimento y zonas verdes (Tabla 1, Figura 11). El análisis se basa en la media y la desviación estándar (SD).

Tabla 1. Tabla de valores de LST $\left({ }^{\circ} \mathrm{C}\right)$ para las cuatro cubiertas significativas por día y hora.

\begin{tabular}{|c|c|c|c|c|c|c|c|c|c|}
\hline \multirow{2}{*}{\multicolumn{2}{|c|}{ Fecha (día y hora GMT+2) }} & \multicolumn{2}{|c|}{ Puntos calientes } & \multicolumn{2}{|c|}{ Edificios } & \multicolumn{2}{|c|}{ Pavimento } & \multicolumn{2}{|c|}{ Zonas verdes } \\
\hline & & $\overline{\bar{x}} \mathrm{LST}$ & SD & $\overline{\bar{x}} \mathrm{LST}$ & SD & $\overline{\bar{x}} \operatorname{LST}$ & SD & $\overline{\bar{x}}$ LST & SD \\
\hline \multirow[t]{3}{*}{$25-26 / 06 / 2008$} & $13: 27 \mathrm{~h}$ & 69,7 & 8,3 & 51,1 & 73,8 & 53,7 & 4,17 & 45,8 & 4,0 \\
\hline & $00: 31 \mathrm{~h}$ & 32,0 & 2,7 & 30,9 & 3,7 & 38,3 & 1,98 & 30,9 & 1,8 \\
\hline & $06: 26 \mathrm{~h}$ & 22,4 & 1,8 & 22,4 & 2,8 & 27,2 & 1,25 & 22,8 & 1,1 \\
\hline \multirow[t]{3}{*}{$01-02 / 07 / 2008$} & $13: 44 \mathrm{~h}$ & 66,3 & 7,1 & 51,4 & 6,6 & 54,1 & 3,76 & 48,3 & 4,5 \\
\hline & $00: 12 \mathrm{~h}$ & 25,6 & 3,4 & 25,0 & 4,7 & 34,3 & 2,21 & 24,3 & 2,3 \\
\hline & $06: 26 \mathrm{~h}$ & 19,1 & 2,6 & 19,7 & 3,8 & 27,3 & 1,85 & 19,8 & 1,9 \\
\hline \multicolumn{2}{|c|}{ Amplitud térmica diaria media } & & 47,3 & & 30,2 & & 26,65 & & 25,7 \\
\hline
\end{tabular}

A partir de datos de DESIREX.

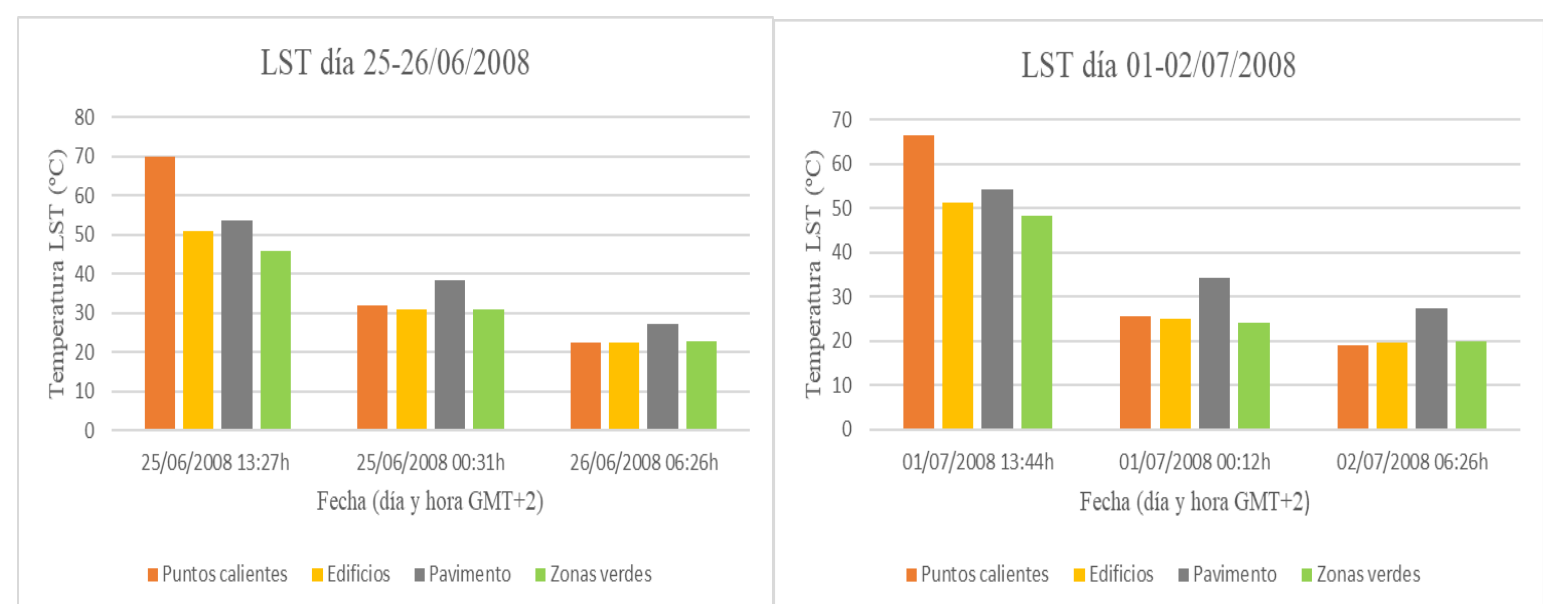

Figura 11. Gráficos de valores medios de LST para las cubiertas de puntos calientes, edificios, pavimento y zonas verdes, por día y hora. A partir de Tabla 1.

Para los dos días analizados, el mediodía es el momento de mayor insolación y por tanto de mayor sobrecalentamiento, mientras que en la noche y la madrugada la LST de las cubiertas disminuye considerablemente, comportándose de forma similar para ambos momentos. La cubierta con mayor LST al mediodía es la de puntos calientes, mientras que en la noche y la madrugada es el pavimento. Se procede a analizar en detalle cada cubierta. 1) Para los puntos calientes, las mayores LST se presentan al mediodía, con valores elevados de $68,0{ }^{\circ} \mathrm{C}$ medios. Estas cubiertas presentan baja resistencia al sobrecalentamiento, pues su LST varía una media de $47,3{ }^{\circ} \mathrm{C}$ entre el mediodía y la madrugada, alcanzando valores medios de LST de $28,8^{\circ} \mathrm{C}$ en la noche y $20,7^{\circ} \mathrm{C}$ en la madrugada. 2) Aquellos edificios que no se comportan como puntos calientes presentan valores de LST menores $\left(51,2^{\circ} \mathrm{C}\right.$ medios a mediodía, $28,0^{\circ} \mathrm{C}$ en la noche y $21,0^{\circ} \mathrm{C}$ en la madrugada) con una media de amplitud térmica diaria de $30,2^{\circ} \mathrm{C}$. 3) El pavimento mantiene su temperatura más o menos constante pero elevada a lo largo de día, con valores medios de amplitud térmica diaria de $26,7^{\circ} \mathrm{C}$ 
Aragoneses de la Rubia, E. (2020). Caracterización de la isla de calor urbana en el campus de la UAM por medio de teledetección. GeoFocus, Revista Internacional de Ciencia y Tecnología de la Información Geográfica, 26, 43-67. http://dx.doi.org/10.21138/GF.678

(menor que la de los edificios) y de LST de $53,9^{\circ} \mathrm{C}$ medios al mediodía, $36,3{ }^{\circ} \mathrm{C}$ en la noche y $27,6^{\circ} \mathrm{C}$ en la madrugada (LST más altas que los edificios que no son puntos calientes). 4) Las zonas verdes reflejan ser las cubiertas con mayor capacidad termorreguladora y resistencia al sobrecalentamiento, con los valores más bajos de amplitud térmica diaria $\left(25,7^{\circ} \mathrm{C}\right.$ medios $)$ y más bajos de LST para todo el día, $\left(47,1^{\circ} \mathrm{C}\right.$ medios al mediodía, $27,6{ }^{\circ} \mathrm{C}$ en la noche y $21,3{ }^{\circ} \mathrm{C}$ en la madrugada). Así pues, en el campus destaca la importancia de los espacios verdes para suavizar las temperaturas (como apuntaron Toy et al. 2005; Hart y Sailor, 2009) y de los materiales artificiales como acumuladores de calor, como ya señaló la campaña DESIREX (Sobrino et al. 2009a).

Asimismo, se emplea la desviación estándar (SD) para analizar la variabilidad de los datos (Tabla 2). Los píxeles correspondientes a puntos calientes presentan la mayor variabilidad de LST a lo largo del día, con valores de SD del doble respecto a las otras cubiertas. Es decir, el tipo de cubierta cuyos píxeles presentan mayor variación en su valor de LST a lo largo del día (heterogeneidad) es la de puntos calientes; mientras que el resto de cubiertas presentan variaciones diarias menores. Además (Tabla 3), el mediodía es la hora en que mayor es la diferencia de LST entre los distintos tipos de cubiertas, existiendo considerables diferencias entre las cubiertas más calientes y las más frías. Por otro lado, en la noche y la madrugada la diferencia térmica entre cubiertas se reduce hasta 2 y 3 veces (3 para el primer día y 2 para el segundo). Así, la LST por cubiertas en el campus presenta cierta heterogeneidad térmica al mediodía que se homogeniza cuando no recibe insolación directa al caer la noche y en la madrugada.

Tabla 2. Desviaciones estándar (SD) internas por cada tipo de cubierta para cada día.

\begin{tabular}{|c|r|r|r|r|}
\cline { 2 - 5 } \multicolumn{1}{c|}{} & Puntos calientes & Edificios & Pavimento & Zonas verdes \\
\hline SD 25-26/06/2008 & 25,0 & 14,7 & 13,3 & 11,7 \\
\hline SD 01-02/07/2008 & 25,6 & 17,0 & 13,9 & 15,3 \\
\hline Media & 25,3 & 15,9 & 13,6 & 13,5 \\
\hline
\end{tabular}

A partir de datos de DESIREX.

Tabla 3. Desviaciones estándar (SD) entre los tres tipos de cubiertas para cada día y hora.

\begin{tabular}{|r|r|r|r|r|r|}
\hline \multicolumn{3}{|c|}{ Primer día analizado } & \multicolumn{3}{c|}{ Segundo día analizado } \\
\hline SD 13:27h & SD 00:31h & SD 06:26h & SD 13:44h & SD 00:12h & SD 06:26h \\
\hline 10,3 & 3,6 & 2,4 & 7,9 & 4,7 & 3,9 \\
\hline
\end{tabular}

A partir de datos de DESIREX.

Como consideración final, para mejorar las cualidades térmicas de edificios y cubiertas construidos y por construir se recomienda incorporar materiales de baja conductividad y alta resistencia térmica. Un material que cumple estos requisitos es el propio aire. Cuanto más aire contenga un material, menor cohesión molecular entre partículas tendrá y por tanto presentará mayor capacidad de aislamiento térmico. Ejemplos de materiales que contienen gran cantidad de aire y que mejorarían las capacidades térmicas de los edificios al emplearse como aislantes en sus cubiertas son: el poliestireno expandido (poliespán), poliestireno extruido, lana de roca, poliuretano, celulosa, fibras minerales o fibra de vidrio. Otra solución es la instalación de fachadas ventiladas que aprovechen las características aislantes del propio aire (incorporar paneles aislantes compuestos de poliespán en la superficie exterior de la fachada, poliestireno extruido o lana mineral; inyectar aislamiento térmico como el poliuretano y la celulosa; incorporar en las paredes internas del edificio 
Aragoneses de la Rubia, E. (2020). Caracterización de la isla de calor urbana en el campus de la UAM por medio de teledetección. GeoFocus, Revista Internacional de Ciencia y Tecnología de la Información Geográfica, 26, 43-67. http://dx.doi.org/10.21138/GF.678

materiales aislantes reflexivos como lana mineral, poliespán, poliestireno extruido o el uso de pinturas especiales que desvíen el calor; instalar doble acristalamiento de baja emisión, etcétera) (Club Español de Energía, 2017). En aquellos edificios que se permita peso adicional en las cubiertas, se pueden instalar jardines en las azoteas, lo que además de termorregular genera otros beneficios ecológicos como filtración de contaminantes y generación de $\mathrm{O}_{2}$. Además, pintar las cubiertas de colores claros incrementa su reflexividad, aumentando el albedo y reduciendo el calor absorbido. Sin embargo, hay que considerar que muchas veces los impedimentos técnicos no son tan limitantes como la normativa urbanística, por lo que se recomienda estudiar caso a caso cada instalación.

\section{Discusión y valoración de hallazgos}

Las imágenes LST se presentan como una metodología muy interesante de aproximación al estudio térmico de enclaves urbanos. Las imágenes derivadas de los datos de DESIREX poseen una resolución espacial adecuada para el estudio preciso del comportamiento térmico de cubiertas, comparado con otros satélites que ofrecen imágenes de menor resolución, como Landsat 8 . La alta frecuencia temporal y espacial de los datos ha permitido una interpolación más precisa de los espacios vacíos en el terreno, con la consiguiente presunción de mejores resultados. Además, la preparación de los datos ha supuesto el control de la mayor parte de las variables implicadas, con un mayor control de la calidad del resultado. Sin embargo, los datos de DESIREX presentan la limitación de corresponder a 2008. Asimismo, la preparación y manejo de los datos de esta campaña ha sido compleja y laboriosa, si se compara con datos ya preparados o casi preparados como los productos de Sentinel-2 y Landsat 8, y puede haber dado lugar a errores inconscientes, pues no están sometidos a los controles rutinarios de las imágenes convencionales descargables de los satélites.

Los resultados obtenidos señalan que el campus de la UAM no parece estar influenciado de manera significativa por la SUHI madrileña, refutando la hipótesis primera de este trabajo. Además, los resultados obtenidos contradicen la idea de que incluso asentamientos pequeños presentan UHIs (como sugerían Bonan, 2000; Oke, 1973 y Svensson, 2004), especialmente los cercanos a Madrid por estar influenciados por su UHI (como sugerían Núñez Peiró et al. 2007). Sin embargo, sí se han observado variaciones térmicas en pequeñas distancias en el campus de la UAM en función del material de construcción y el tipo de uso del suelo, corroborando las ideas de Hartz et al. (2005) y Fernández García y Rasilla Álvarez (2008), y la hipótesis inicial de este trabajo. Asimismo, se ratifica la hipótesis de la importante labor termorreguladora de los espacios verdes del campus.

En este trabajo, la caracterización de la UHI del campus de la UAM sirve como primer paso para mejorar la gestión térmica del campus. Asimismo, puede servir como base de dos objetivos. Por un lado, la caracterización de los materiales y estructuras urbanas en función de la respuesta más o menos efectiva a la amortiguación térmica de la UHI y, por otro lado, la toma de conciencia de la necesidad de actuación para la prevención del riesgo asociado a estrés térmico. Además, sienta las bases para futuras investigaciones que desbordan la envergadura de esta: 1) elaboración de un mapa del campus de zonas prioritarias de actuación según su clasificación en niveles de estrés térmico, y 2) establecimiento de retos y propuestas de gestión para mejorar la calidad de vida de las personas que a diario pasan tiempo en el campus y en los edificios considerados puntos calientes. 
Aragoneses de la Rubia, E. (2020). Caracterización de la isla de calor urbana en el campus de la UAM por medio de teledetección. GeoFocus, Revista Internacional de Ciencia y Tecnología de la Información Geográfica, 26, 43-67. http://dx.doi.org/10.21138/GF.678

Entender el comportamiento térmico de cualquier lugar es fundamental para comprender las dinámicas existentes y mejorar la calidad de vida de sus habitantes. Destacan las imágenes LST como método adecuado para facilitar la visualización de información térmica, en combinación con imágenes NDVI. Es necesario continuar avanzando en este tipo de estudios para determinar la posibilidad de la teledetección como sustituto de los sensores de terreno, incluso para ciudades con una red de calidad. También se debe investigar si los resultados obtenidos mejorarían al mezclarlos con otras variables como altitud, densidad de edificación, altura de edificios, etcétera. Pese a estos aun inconvenientes, se subraya el potencial de la teledetección en ciudades no occidentales carentes de registros en el terreno. Este es un punto central de investigaciones actuales para satélites futuros.

\section{Conclusiones}

El efecto de la SUHI en la UAM no presenta las mismas características que la UHI madrileña, no existiendo como tal en el campus. El campus de la UAM no presenta isla de calor e isla de frío, como sí hace la capital. Las zonas que rodean al campus no presentan valores más bajos de LST durante el día y más altos durante la noche en comparación con el campus, sino que son determinadas superficies y cubiertas artificiales las que, en líneas generales, presentan los valores más altos de LST durante todo el día (los puntos calientes a mediodía y el pavimento en la noche y la madrugada). Pese a su cercanía a la gran urbe, el campus se comporta térmicamente como un espacio rural en lugar de como una ciudad. En términos generales, se comporta de forma similar a El Pardo y la Casa de Campo, aunque con variaciones espaciales según el tipo de cubierta. Esto se puede deber a que el campus de la UAM 1) es un enclave de menor tamaño con menor capacidad de influencia ambiental, 2) presenta cierta lejanía respecto a la urbe madrileña, no viéndose afectado por su SUHI, y 3) la superficie construida del campus contiene multitud de espacios verdes intercalados que favorecen la termorregulación de la zona promoviendo la continuidad superficial entre el campus y su entorno no urbanizado. Además, destaca la heterogeneidad de LST de las distintas cubiertas al mediodía y la homogeneización de estas en la noche y la madrugada. También se distinguen diferentes comportamientos de las cubiertas artificiales. Algunas están muy influidas por la insolación (puntos calientes y edificios), y otras mantienen su temperatura con mayor independencia de la radiación solar incidente (pavimento). En cambio, los espacios verdes destacan por su capacidad termorreguladora.

Asimismo, este trabajo ofrece un primer análisis de la problemática en el campus de la UAM, identificando las características de los puntos calientes y el pavimento, sobre los que se sugiere actuación, y sirve de contexto para mejorar la gestión del campus y la calidad de habitabilidad de los espacios. Los puntos calientes son espacios donde se requiere actuación porque 1) alcanzan valores máximos de LST a mediodía, siendo este un periodo en que estos espacios están habitados de forma importante, y 2) presentan los mayores valores de amplitud térmica diaria, sugiriendo que es posible realizar actuaciones que favorezcan la termorregulación y mitiguen el sobrecalentamiento de las cubiertas. El pavimento es otro importante foco de calor porque mantiene su temperatura relativamente constante y elevada a lo largo del día, cuya emisión de calor destaca sobre todo en la noche y la madrugada. Como primeras medidas de mitigación, se sugiere conservar y ampliar las zonas verdes del campus con vegetación densa y vigorosa con elevada evapotranspiración (árboles de sombra y arbustos con riego artificial) y NDVI $\geq 0,4$, y revestir el 
Aragoneses de la Rubia, E. (2020). Caracterización de la isla de calor urbana en el campus de la UAM por medio de teledetección. GeoFocus, Revista Internacional de Ciencia y Tecnología de la Información Geográfica, 26, 43-67. http://dx.doi.org/10.21138/GF.678

pavimento y las cubiertas de los edificios caracterizados como puntos calientes con otros de mayor resistencia al sobrecalentamiento y reflectantes (con colores claros).

En resumen, el estudio de la isla de calor urbana superficial (SUHI) con teledetección es una técnica de gran interés para estudios térmicos. Las principales causas del sobrecalentamiento de las cubiertas de un enclave urbano son los usos del suelo y su transformación en tejido urbano. Para el caso de la temperatura del campus de la UAM, esta no parece estar influenciada de forma significativa, pese a su cercanía, por la UHI madrileña. El campus universitario se comporta de forma similar a las zonas rurales, no existiendo isla de calor diurna y nocturna. En el campus de la UAM, las zonas arboladas y los materiales de las cubiertas son de gran relevancia para determinar las características térmicas del espacio. En este sentido, existen importantes diferencias de temperaturas alcanzadas a lo largo del día y de amplitud térmica en función del uso del suelo y material de construcción de las cubiertas. Como consideración final, la caracterización de la isla de calor urbana de un emplazamiento concreto es necesaria para una correcta gestión del territorio. Es esencial conocer las características térmicas de los espacios para el diseño de ciudad habitable, eficiente, y para prevención de riesgos y mejora de calidad de vida.

\section{Agradecimientos}

Agradezco al Dr. José Antonio Rodríguez Esteban por su tutela. También al equipo del Área de Teledetección del INTA y a Eduardo de Miguel Llanes por su ayuda que posibilitó el ir varios días a sus instalaciones para conseguir los datos necesarios, así como la utilización del software específico de dicha institución, mostrándose siempre dispuestos a dar el soporte necesario para llevar a cabo este trabajo.

\section{Referencias bibliográficas}

Anandababu, D; Purushothaman, B. M. y Suresh, B. D. (2018). Estimation of land surface temperature using Landsat 8 data, International journal of advance research, ideas and innovations in technology, 4, 2, 177-186.

Avdan, U. y Jovanovska, G. (2016). Algorithm for automated mapping of land surface temperature using Landsat 8 satellite data, Journal of sensors, 2016.

Bonan, G. B. (2000). The microclimates of a suburban Colorado (USA) landscape and implications for planning and design, Landscape and urban planning, 49, 97-114.

Bottyán, Z. y Unger, J. (2003). "A multiple linear statistical model for estimating the mean maximum urban heat island", Theoretical and applied climatology, 75, 233-243.

Carretero, L. y De Miguel, E. (2015). "Evaluación de algoritmos de separación temperatura/emisividad en imágenes sintéticas AHS” en XVI Congreso de la asociación española de teledetección. Teledetección: humedales y espacios protegidos. Libro de actas. Sevilla 21-23 octubre 2019, 232-235. 
Aragoneses de la Rubia, E. (2020). Caracterización de la isla de calor urbana en el campus de la UAM por medio de teledetección. GeoFocus, Revista Internacional de Ciencia y Tecnología de la Información Geográfica, 26, 43-67. http://dx.doi.org/10.21138/GF.678

Club español de energía (2017). Energía y ciudades. Club español de la energía. Madrid.

Cochrane, M- A. (2000). Using vegetation reflectance variability for species level classification of hyperspectral data, International journal of remote sensing, 21, 10, 20752087.

Danson, F. M. (1995). "Developments in the remote sensing of forest canopy structure" en Danson F. M y Plummer, S. E.: Advances in environmental remote sensing. Oceanographic literature review, 8, 43, 53-69.

Data user element (2008). Satellite observations help lessen the effects of heatwaves in urban area. News. Data user element. ESA. [Consulta: 04-10-2019]. Disponible en: http://due.esrin.esa.int/page news168.php consultado el 04/10/2019

ESA (2019). Copernicus open sci hub. ESA. [Consulta: 15-10-2019]. Disponible en: https://scihub.copernicus.eu/dhus/\#/home

ESA (2020). Sentinel-2. Satellite description. ESA [consulta: 08-09-2020]. Disponible en: https://sentinel.esa.int/web/sentinel/missions/sentinel-2/satellite-description

EPA (2003). Beating the heat: mitigating thermal impacts, Nonpoint source news-notes, 72, 23-26.

Eurosocial (2015). Grupos vulnerables: Informe sobre el abordaje de la vulnerabilidad en EUROsociAL. FIIAP. [Consulta: 08-06-2020]. Disponible en: http://sia.eurosocialii.eu/files/docs/1447416430-informe_grupos\%20vulnerables.pdf

Fernández García, F.; Montálvez, J. P.; González Rouco, F. J. et al. (2003). “A pca analysis of the UHI form of Madrid (Spain)" en 5th International Conference on urban climate, 15/9, Lodz, Polonia.

Fernández García, F.; Allende Álvarez, F.; Rasilla Álvarez, D. et al. (2016). Estudio de detalle del clima urbano de Madrid. Madrid, Universidad Autónoma de Madrid, departamento de Geografía.

Fernández García, F. y Rasilla Álvarez, D. (2008). Olas de calor e influencia urbana en Madrid y su área metropolitana, Estudios geográficos, 69, 265, 495-518.

Fernández García, F. y Rasilla Álvarez, D. (2012). “Confort térmico e influencia urbana en el área metropolitana de Madrid” en Nuevos aires de la geografía española del siglo XXI. Aportación española al XXXII ${ }^{\circ}$ Congreso de la Unión Geográfica Internacional. Editorial Comité Español de la ugi/2012.

Génova Fuster, M. M. (1989). Flora vascular del monte de Valdelatas y su entorno, Ecología, 3, 75:98.

Gillespie, A.; Rokugawa, S.; Matsunaga, T. et al. (1998). A temperature and emissivity separation algorithm for advanced spaceborne thermal emission and reflection radiometer (ASTER) images. IEEE transactions on geoscience and remote sensing, 36, 4, 1113-1126. 
Aragoneses de la Rubia, E. (2020). Caracterización de la isla de calor urbana en el campus de la UAM por medio de teledetección. GeoFocus, Revista Internacional de Ciencia y Tecnología de la Información Geográfica, 26, 43-67. http://dx.doi.org/10.21138/GF.678

Gillespie, A.; Rokugawa, S.; Hook, S. J. et al. (1999). Temperature/emissivity separation algorithm theoretical basis document, version 2.4. ATBD contract NAS5-31372, NASA.

Gómez Mendoza, J.; Luna, G; Mas, R. et al. (1987). Guettos universitarios. el campus de la Universidad Autónoma de Madrid. Madrid, Ediciones de la Universidad Autónoma, colección de bolsillo 7.

Green Urban Data (2019): Zonas verdes: ¿cantidad o calidad?. Green urban data. [Consulta: 24-05-2020]. Disponible en: https://www.greenurbandata.com/2019/02/07/zonas-verdes-cantidad-o-calidad/

Hartz, D. A.; Prashad, L.; Hedquist, B. C. et al. (2006). Linking satellite images and handheld infrared thermography to observed neighborhood climate conditions, Remote sensing of environment, 104, 190-200.

Hart, M. A. y Sailor, D. J. (2009). Quantifying the influence of land-use and surface characteristics on spatial variability in the urban heat island, Theoretical and applied climatology, 95, 3-4, 397-406.

Huang, H. Ooka, R. y Kato, S. (2005). Urban thermal environment measurements and numerical simulation for an actual complex urban area covering a large district heating and cooling system in summer, Atmospheric environment, 39, 6362-6375.

IGN. Centro de descargas del IGN. [Consulta: 05-10-2019]. Disponible en: http://centrodedescargas.cnig.es/centrodescargas/index.jsp\#

IGME. Cartografia del IGME. [Consulta: 05-10-2019]. Disponible en: http://info.igme.es/cartografiadigital/geologica/magna50.aspx

INE. [Consulta: 23-05-2020]. Disponible en: https://www.ine.es/

Kachhwaha, T. S. (1883). Spectral signatures obtained from Landsat digital data for forest vegetation and land-use mapping in India, Photogrammetric engineering and remote sensing, 49, 5, 685-689.

Laaidi, K.; Zeghnoun, A.; Dousset, B. et al. (2012). The impact of heat islands on mortality in Paris during the august 2003 heat wave, Environmental health perspectives, 120, 254259.

Levin, N. y Phinn, S. (2016). Illuminating the capabilities of Landsat 8 for mapping night lights, Remote sensing of environment, 182, 27-38.

López Gómez, A.; Fernández García, F. y Moreno Jiménez, A. (1993). El clima urbano. teledetección de la isla de calor en Madrid. Madrid, Ministerio de obras públicas y transportes, serie monografías.

López Gómez, A.; López Gómez, J.; Fernández García, F. et al. (1991). El clima urbano de Madrid: la isla de calor, Editorial CSIC_CSIC press. 
Aragoneses de la Rubia, E. (2020). Caracterización de la isla de calor urbana en el campus de la UAM por medio de teledetección. GeoFocus, Revista Internacional de Ciencia y Tecnología de la Información Geográfica, 26, 43-67. http://dx.doi.org/10.21138/GF.678

Masek, J. F.; Taylor, M. P. y Rocchio, L. (2019). Landsat 8. NASA. Landsat science. [Consulta: 16-10-2019]. Disponible en: https://landsat.gsfc.nasa.gov/landsat-datacontinuity-mission/

Martínez Vega, J.; Martín, M. P.; Díaz Montejo, J. M. et al. (2010). Guía didáctica de teledetección y medio ambiente, Centro de ciencias humanas y sociales (CSIC).

Mirzaei, P. A. y Haghighat, F. (2010). Approaches to study urban heat island-abilities and limitations, Building and environment, 45, 2192-2201.

Morris, C. J- G.; Simmonds, I. y Plummer, N. (2001). Quantification of the influences of wind and cloud on the nocturnal urban heat island of a large city, Journal of applied meteorology, 40, 169-182.

Núñez Peiró, M.; Román López, M. E.; Sánchez Guevara, C. et al. (2016). Hacia un modelo dinámico para la isla de calor urbana de Madrid, Anales de edificación, 2, 1, 49-58.

Núñez Peiró, M.; Sánchez Guevara, C. y Neila González, F. J. (2017). Actualización de la isla de calor urbana de madrid y su influencia en la simulación energética de edificios" en 3er Congreso Internacional de construcción sostenible y soluciones eco-eficientes, Libro de Actas, 890-901, Sevilla: Universidad de Sevilla, Escuela técnica superior de arquitectura.

Oke, T. R. (1973). City size and the urban heat island, Atmospheric environment, 7, 769779 .

Oke, T. R. (1982). The energetic basis of the urban heat island, Quarterly journal of the royal meterological society, 108, 1-24.

Pérez González, M. E.; García Rodríguez, M. P. y Guerra Zaballos, A. (2003). Análisis del clima urbano a partir de imágenes de satélite en el centro peninsular español, Anales de geografia de la Universidad Complutense, 23, 187-206.

Pérez González, M. E. y García Rodríguez, M. P. (2001). Estudio de las bandas térmicas del ETM en la Comunidad de Madrid y alrededores. Asociación española de climatología.

Population Reference Bureau (2019). 2019 world population data sheet. Population reference bureau.

Price, J. C. (1994). How unique are spectral signatures?, Remote sensing of environment, 49, 3, 181-186.

Rasul, A.; Balzter, H.; Smith, C. et al. (2017). A review on remote sensing of urban heat and cool islands, Land, 6, 2, 38.

Roa, P. K. (1972). Remote sensing of urban" heat islands" from an environmental satellite, Bulletin of the American Meteorological Society, 53, 647-648. 
Aragoneses de la Rubia, E. (2020). Caracterización de la isla de calor urbana en el campus de la UAM por medio de teledetección. GeoFocus, Revista Internacional de Ciencia y Tecnología de la Información Geográfica, 26, 43-67. http://dx.doi.org/10.21138/GF.678

Sailor, D. J. y Lu, L. (2004). A top-down methodology for developing diurnal and seasonal anthropogenic heating profiles for urban areas, Atmospheric environment, 38, 2737-2748.

Sánchez González, D. y Chávez Alvarado, R. (2016). "Adjustments to physical-social environment of the elderly to climate change: proposals from environmental gerontology" en Sácnhez González, D.; Chávez Alvarado, R.: Environmental gerontology in Latin America and Europe. Policies and perspectives on environment and aging. Nueva York, 105-126.

Sánchez González, D. y Chávez Alvarado, R. (2019): "Vulnerabilidad de las personas mayores al cambio climático" en Sánchez González, D. y Chávez Alvarado, R.: Envejecimiento de la población y cambio climático. Vulnerabilidad y resiliencia desde la gerontología ambiental. Granada: Comares, 119-175.

Sarrat, C.; Lemonsu, A.; Masson, V. et al. (2006). Impact of the urban heat island on regional atmospheric pollution, Atmospheric environment, 40, 1743-1758.

Sobrino, J. A.; Bianchi, R.; Paganini, M. et al. (2009a): DESIREX 2008 final report. ESA.

Sobrino, J. A.; Sòria, G.; Oltra Carrió, R. et al. (2009b). DESIREX 2008: estudio de la isla de calor en la ciudad de Madrid, Revista de teledetección, 31, 80-92.

Sobrino, J.A.; Oltra Carrió, R.; Sòria, G. et al. (2013). Evaluation of the surface urban heat island effect in the city of Madrid by thermal remote sensing, International journal of remote sensing, 34, 3177-3192.

Stone, B. y Norman, J. M. (2006). Land use planning and surface heat island formation: a parcel-based radiation flux approach, Atmospheric environment, 40, 3561-3573.

Svensson, M. K. (2004). Sky view factor analysis-implications for urban air temperature differences, Meteorological applications, 11, 201-211.

Sykas, D. (2018a). Thermal hyperspectral images. Part of the course notes: hyperspectral thermal image unmixing. Geo university. [Consulta: 04-10-2019]. Disponible en: https://www.geo.university/courses/hyperspectral-thermal-image-unmixing

Sykas, D. (2018b): Thermal theory concepts. Part of the course notes: hyperspectral thermal image unmixing. Geo university. [Consulta: 04-10-2019]. Disponible en: https://www.geo.university/courses/hyperspectral-thermal-image-unmixing

Taha, H. (1997). Urban climates and heat islands: albedo, evapotranspiration, and anthropogenic heat, Energy and buildings, 25, 99-103.

Toy, S.; Yilmaz, S. y Yilmaz, H. (2007). Determination of bioclimatic comfort in three different land uses in the city of Erzurum, Turkey, Building and environment, 42, 13151318 .

Tucker, C. J. y Garratt, M. W. (1977). Leaf optical system modeled as a stochastic process, Applied optics, 16, 3, 635-642. 
Aragoneses de la Rubia, E. (2020). Caracterización de la isla de calor urbana en el campus de la UAM por medio de teledetección. GeoFocus, Revista Internacional de Ciencia y Tecnología de la Información Geográfica, 26, 43-67. http://dx.doi.org/10.21138/GF.678

Unger, J. (2006). Modelling of the annual mean maximum urban heat island using $2 \mathrm{~d}$ and 3d surface parameters, Climate research, 30, 215-226.

United Nations (2019a). World urbanization prospects 2018: highlights. Department of economics and social affairs. United Nations. Nueva York, 2019.

United Nations (2019b). World populations prospects 2019: highlights. Department of economics and social affairs. United Nations. Nueva York, 2019.

USGSa. Glovis. NASA. [Consulta: 18-10-2019]. Disponible en: https://glovis.usgs.gov/app

USGSb. Landsat level-1 processing details. NASA. [Consulta: 24-05-2020]. Disponible en: https://www.usgs.gov/land-resources/nli/landsat/landsat-level-1-processing-details

USGSc. (2019). USGS eros archive- Sentinel-2. NASA. [Consulta: 20-10-2019]. Disponible en: https:/www.usgs.gov/centers/eros/science/usgs-eros-archive-sentinel-2?qtscience center objects $=0 \#$ qt-science center_objects

Voogt, J. A. (2002). Urban heat island: causes and consequences of global environmental change. Wiley, Chichester, Nueva York: 2, 660-666.

Voogt, J. A. y Oke, T. R. (2003). Thermal remote sensing of urban climates, Remote sensing of environment, 86, 370-384.

Zanter, K. (2019). Landsat 8 surface reflectance code (lasrc) product guide. version 2. Department of the interior. US geological survey. USGS. Sioux falls. Dakota del sur. [Consulta: 17-10-2019]. Disponible en: https://prd-wret.s3.us-west2.amazonaws.com/assets/palladium/production/atoms/files/LSDS-1368 L8 C1-

$\underline{\text { LandSurfaceReflectanceCode-LASRC ProductGuide-v3.pdf }}$ 
